Predicting returns and rent growth in the housing market using the rent-to-price ratio: Evidence from the OECD countries

\author{
Tom Engsted and Thomas Q. Pedersen
}

CREATES Research Paper 2012-58 


\title{
Predicting returns and rent growth in the housing market using the rent-to-price ratio: Evidence from the OECD countries*
}

\author{
Tom Engsted ${ }^{\dagger} \quad$ Thomas Q. Pedersen ${ }^{\ddagger}$
}

December 2012

\begin{abstract}
We investigate the predictive power of the rent-to-price ratio for future real estate returns and rent growth in 18 OECD countries over the period 1970 to 2011. First, we document that in most countries returns are significantly predictable by the rentprice ratio. An increase (decrease) in the ratio signals a future increase (decrease) in returns. Second, there are large cross-country differences in how the rent-price ratio predicts rent growth. For some countries the direction of predictability is negative, for other countries it is positive. Third, the predictive patterns are highly dependent on whether returns and rents are measured in nominal or real terms. Finally, there is some evidence of sub-sample instability in the predictive patterns, especially wrt. rent growth predictability. The predictability tests are conducted within a restricted VAR framework based on the dynamic Gordon growth model. This model implies restrictions across the VAR parameters that can be used to construct powerful tests of predictability.
\end{abstract}

JEL Classification: C32, G12, R31

Keywords: Real estate predictability, dynamic Gordon growth model, rent-price ratio, VAR model, OECD countries

${ }^{*}$ This research is supported by CREATES (Center for Research in Econometric Analysis of Time Series), funded by the Danish National Research Foundation. We thank Jérôme Brezillon for providing us with the OECD data.

${ }^{\dagger}$ CREATES, Department of Economics and Business, Aarhus University, Fuglesangs Allé 4, DK-8210 Aarhus V, Denmark. E-mail: tengsted@creates.au.dk.

${ }^{\ddagger}$ CREATES, Department of Economics and Business, Aarhus University, Fuglesangs Allé 4, DK-8210 Aarhus V, Denmark. E-mail: tqpedersen@creates.au.dk. 


\section{Introduction}

Standard textbook models of price determination in real estate markets imply that rents are a fundamental determinant of housing value, similar to the role of dividends in determining equity valuations in stock markets, and the rent-to-price ratio (sometimes denoted the 'cap rate') summarizes market expectations of future real estate returns and/or rent growth in the same way as the dividend-price ratio summarizes expectations of future stock returns and/or dividend growth. A number of recent studies have analyzed the predictive power of the rent-to-price ratio for future returns and rent growth in the US real estate market, e.g. Gallin (2008), Plazzi, Torous, and Valkanov (2010), Cochrane (2011), and Ghysels, Plazzi, Torous, and Valkanov (2012). The overall finding is that the rent-to-price ratio predicts future returns more strongly than it predicts future rent growth, just as the dividend-price ratio appears to be a stronger predictor of returns than dividend growth in the US stock market (Cochrane, 2011). ${ }^{1}$

Whether the rent-to-price ratio predicts future returns or rent growth is of fundamental importance for the interpretation of price movements in real estate markets. The dramatic increase in US house prices up to 2006 (followed by a severe drop) must be due to one of the following three causes (or a combination of them). Either a speculative bubble, changing expectations of future returns (e.g. due to changing risk premia), or changing expectations of future fundamentals. The empirical evidence cited above points to the second of these causes as the most important, although Shiller (2005) argues that an irrational bubble was the main driver, while Himmelberg, Mayer, and Sinai (2005) on the other hand argue that the price increases were caused by 'strong' fundamentals.

Almost all studies in this area have focused on the US housing market. Very little is known about the rent-to-price ratios predictive power for real estate returns and rents in other countries. Many other countries have experienced similar house price movements as in the US, with dramatic increases up to around 2006 followed by a severe decrease. Thus, there is a clear international dimension to the movements we have seen in housing markets during the last 15 years. It is obviously of interest to examine whether the predictive patterns documented for the US are in fact an international phenomenon, or whether the US experience is the exception rather than the rule. It is well-documented that regarding movements in financial markets, the US is in many ways an 'outlier' compared to many other countries, see e.g. Hardouvelis (1994) and Engsted and Pedersen (2010), respectively, for cross-country studies of the term structure of interest rates and

\footnotetext{
${ }^{1}$ Ghysels et al. (2012) give a detailed survey of the literature on predictability in real estate markets.
} 
predictability in stock markets. In the present paper we carry out a detailed cross-country analysis of predictability in housing markets.

We use annual and quarterly data from 1970 to 2011 for 18 OECD countries to investigate the predictive power of the rent-to-price ratio for future real estate returns and rent growth. Based on the 'dynamic Gordon growth model' (Campbell and Shiller, 1988) - in which the log rent-to-price ratio equals the present discounted value of expected future log returns and rent growth -, and using the restricted vector-autoregressive (VAR) framework from Cochrane (2008), we test whether the log rent-to-price ratio significantly predicts future log returns and/or rent growth. The Campbell-Shiller model implies restrictions across the VAR coefficients which can be used to formulate more powerful tests than those based on standard single-equation regressions in most of the earlier literature. Essentially the tests exploit the fact that if there are no bubbles, unpredictable rent growth must imply predictable returns - and vice versa (cf. Cochrane, 2008).

We analyze predictability of both nominal and real variables. It is well-known that predictability in equity markets is highly dependent on whether stock returns and dividends are measured in nominal or real terms, and this difference is due to predictability of inflation, cf. Engsted and Pedersen (2010). To our knowledge, this issue has not previously been investigated for real estate markets. In addition, motivated by the apparent changes in the relation between house prices and rents in the mid 1990s, we conduct a sub-sample analysis (using quarterly data) of the rent-price ratio's predictive power. ${ }^{2}$

The main findings of our analysis are as follows. First, we document strong crosscountry differences in the predictability of real estate returns and rent growth by the rent-to-price ratio. For the majority of countries the rent-price ratio significantly predicts returns in the 'right' direction, i.e. an increase (decrease) in the ratio signals a future increase (decrease) in returns. For only a few countries there is no evidence of return predictability or significant predictability with the 'wrong' sign. However, regarding rent growth predictability, the cross-country differences are very pronounced. For one large group of countries an increase (decrease) in the rent-price ratio significantly predicts a decrease (increase) in rent growth, while for another large group there is significant predictability in the opposite direction. Second, for many countries the predictability patterns are highly dependent on whether returns and rents are measured in nominal or real terms, and this is due to inflation being strongly predictable by the rent-price

\footnotetext{
${ }^{2}$ Girouard, Kennedy, van den Noord, and André (2006) perform an informal (graphical) analysis of overvaluation, based on the rent-to-price ratio, in the 18 OECD countries using the same data up to 2005. They do not conduct formal (econometric) analyses of the rent-to-price ratio's predictive power.
} 
ratio. For most countries both nominal and real returns are significantly predictable, but for many countries nominal rent growth predictability with a positive sign is turned into real rent growth predictability with a negative sign. Finally, we document some sub-sample instability in the predictive patterns, especially with respect to rent growth predictability. In addition, this instability is to some extent cross-country dependent and dependent on whether returns and rent growth are measured in nominal or real terms. To the best of our knowledge these strong cross-country differences, and the sensitivity of predictability results to whether variables are measured in nominal or real terms, have not been noticed in the existing literature on predictability in real estate markets.

The rest of the paper is organized as follows. Section 2 describes the OECD database and reports summary statistics of these data. Section 3 gives a description of the loglinear present value relation for the rent-to-price ratio and of the econometric methods we use for examining predictability. The empirical results are reported in section 4 and, finally, section 5 contains some concluding remarks. The appendix contains graphical depictions of the predictability patterns found.

\section{Data}

We analyze return and rent growth predictability for 18 OECD countries: Australia, Belgium, Canada, Switzerland, Germany, Denmark, Spain, Finland, France, UK, Ireland, Italy, Japan, Holland, Norway, New Zealand, Sweden, and US. The dataset provided by the OECD contains quarterly observations from 1970Q1 to 2011Q4 for all countries, except Australia (begins 1972Q3), Belgium (begins 1976Q2), Spain (begins 1971Q1), Norway (begins 1979Q1), and Sweden (begins 1980Q1). The dataset contains seasonally adjusted real and nominal house prices and the rent-price ratio. Based on real and nominal house prices we back out inflation in each country, and from the house prices and the rent-price ratio we can calculate real and nominal rent growth as well as returns. Returns are calculated in the usual way $H_{t+1}=\left(P_{t+1}+R_{t+1}\right) / P_{t}$, where $P_{t+1}$ is the house price at $t+1$ and $R_{t+1}$ the rent at time $t+1$. For the main part of our analysis we use annual rather than quarterly data. The annual house price is the fourth quarter house price and the annual rent for the corresponding year is the sum of rents throughout the year. Based on this annual dataset we can again calculate real and nominal rent growth and returns. In a robustness and sub-sample analysis we use the quarterly dataset.

Table 1 shows descriptive statistics for each country using the annual dataset. Panel 
A reveals large cross-country differences in terms of the nominal return on the real estate market. Countries like Switzerland, Germany, and Japan have all experienced relatively low average yearly returns of around $6-7 \%$ as well as relatively low volatility. In contrast the average nominal return on real estate in Spain and Ireland is more than $20 \%$ with relatively high volatility. Turning to price growth we observe a similar pattern in terms of cross-country differences. For example, for Switzerland, Germany, and Japan mean nominal price growth is around 2-3\% while for Spain and Ireland it is around 9-11\%. In contrast rent growth appears to be much more aligned across the 18 countries. We do observe some cross-country differences but compared to returns and price growth they are of a much smaller magnitude.

Evaluating returns, rent growth, and price growth in real rather than nominal terms we find similar results (Panel B), just with lower means due to inflation (Panel C). As the only country Germany has experienced a decrease in real house prices from 1970 to 2011, while negative real rent growth has occured in a few countries (Canada, Spain, Finland, and Italy).

The nominal series are generally characterized by very high positive autocorrelation. Part of this stems from inflation but as seen in Panel B the real series also display high positive autocorrelation. This can partly be attributed to the construction of the real estate price indices which generates measurement errors. Further, the high transactions costs in housing markets may generate short-term inefficiencies in the form of serially correlated returns. Case and Shiller (1989) also noticed the high positive autocorrelation of housing returns. ${ }^{3}$ For the rent growth series a possible explanation of the high positive autocorrelation could be the regulation of rental markets in many countries.

Turning to the rent-to-price ratio, Figure 1 shows the real house price and rent series for all 18 countries, while Figure 2 shows the corresponding ratio of the two series. The vast majority of countries have experienced the same price development over the sample period. Prices increased slowly from 1970 to around the mid 1990s, where the growth rates in prices increased dramatically. Since 2006 these countries have experienced either negative or (close to) zero growth in prices. In Japan, Germany, and Switzerland, however, prices have behaved quite differently. Japan experienced high growth rates in the 1980s building up to a peak in the price of real estate in 1990 after which prices have decreased continuously. The price development in Switzerland is very similar except that prices have slowly recovered since the turn of the century. Germany has experienced

\footnotetext{
${ }^{3}$ Ghysels et al. (2012) give a survey of different types of real estate price indices, including an overview of the construction methodology and the resulting indices' time series properties.
} 
short-lived build-ups in prices around 1980 and in the mid 1990s. However, since the mid 1990s prices have decreased quite dramatically with a small recovery in recent years.

The rent series generally display similar movements (although of a different magnitude) to the individual countries' house prices. Some exceptions include Japan where rents have increased throughout the sample period, Germany where rents have been more or less constant since the mid 1990s, and Switzerland where rents increased when prices decreased in the 1990s. These differences between Japan, Germany, and Switzerland and the remaining countries are also visible in the rent-price ratio as seen in Figure 2. Where the vast majority of countries have experienced large decreases in the rent-price ratio since at least the mid 1990s it has increased in these three countries. For Switzerland, though, it has decreased slightly since the turn of the century.

Although price and rent have displayed similar movements over time for most countries the rent-price ratio clearly shows that the build-up in prices throughout the 1990s was disconnected from rents in the real estate market, which could suggest the presence of bubbles. A few countries like the US, Ireland, and Denmark have experienced at least a partial recovery of the rent-price ratio, but for most countries it was still historically low in 2011. The US stands out since the rent-price ratio in 2011 was back around its historical mean. Evaluating the descriptive statistics of the rent-price ratio most countries appear very similar. Belgium and Japan stand out since their first-order autocorrelation coefficient is above 1.

\section{$3 \quad$ Methodology}

In this section we describe the methodologies that we use in analyzing predictability of returns and rent growth, including the theoretical motivation for using the rent-price ratio as predictor.

\subsection{The log-linear return approximation}

Using a linearization of the definition of the one-period log stock return, Campbell and Shiller (1988) derive an approximate identity relating log returns to log dividend growth and the log dividend-price ratio. ${ }^{4}$ Applying this approach to the return on real estate we

\footnotetext{
${ }^{4}$ Engsted, Pedersen, and Tanggaard (2012) show that the Campbell-Shiller approximate identity is highly accurate, even with a nonstationary dividend-price ratio.
} 
obtain the following linear relation

$$
h_{t+1}=\Delta r_{t+1}+\left(r_{t}-p_{t}\right)-\rho\left(r_{t+1}-p_{t+1}\right)+c,
$$

where $h_{t+1}, r_{t+1}$, and $p_{t+1}$ denote log return, log rent, and log house price, respectively, $\rho=e^{E[\Delta r-h]}$, and $c$ is a linearization constant. ${ }^{5}$

Iterating (1) forward, imposing a no-bubble transversality condition $\lim _{j \rightarrow \infty} \rho^{j}\left(r_{t+j}-p_{t+j}\right)=$ 0 , and taking conditional expectations, we get the following present value relation

$$
r_{t}-p_{t}=E_{t} \sum_{j=0}^{\infty} \rho^{j}\left(h_{t+1+j}-\Delta r_{t+1+j}\right)-\frac{c}{1-\rho}
$$

According to (2) the rent-price ratio will be a good predictor of future returns and/or rent growth. Thus, given forward-looking expectations and no bubbles, there is a sound theoretical argument as to why the rent-price ratio should predict future returns and/or changes in rent. Existing stock return predictability studies usually refer to the stock market equivalent to (2), which relates the dividend-price ratio to future returns and dividend growth, as the underlying theoretical framework. The economic intuition behind (2) is that, holding expected returns constant, an increase in expected future rent leads to an increase in today's house price and thereby to a decrease in the rent-price ratio. Similarly, holding expected rent growth constant, an increase in expected future returns must imply a lower price today and thereby an increase in the rent-price ratio.

Equation (2) holds for both nominal and real variables. If we define log inflation from time $t$ to $t+1$ as $\pi_{t+1}$, we can write (2) as

$$
r_{t}-p_{t}=E_{t} \sum_{j=0}^{\infty} \rho^{j}\left[\left(h_{t+1+j}-\pi_{t+1+j}\right)-\left(\Delta r_{t+1+j}-\pi_{t+1+j}\right)\right]-\frac{c}{1-\rho} .
$$

This equation shows that if the rent-price ratio forecasts nominal and real returns or rent growth differently, then it must be due to the rent-price ratio having predictive power for future inflation. For example, if nominal returns are not predictable but inflation is, then the result must be that real returns are predictable.

\footnotetext{
${ }^{5}$ Other studies that apply the approach by Campbell and Shiller (1988) on real estate returns include Campbell, Davis, Gallin, and Martin (2009), Plazzi et al. (2010), and Ghysels et al. (2012).
} 


\subsection{Predictability regressions and joint hypothesis testing}

Motivated by the present value relation (2) we use a restricted first-order vector autoregressive (VAR) model to examine predictability of returns and rent growth by the rent-price ratio

$$
\begin{aligned}
h_{t+1} & =a_{h}+b_{h}\left(r_{t}-p_{t}\right)+\varepsilon_{h, t+1}, \\
\Delta r_{t+1} & =a_{r}+b_{r}\left(r_{t}-p_{t}\right)+\varepsilon_{r, t+1}, \\
r_{t+1}-p_{t+1} & =a_{r p}+\phi\left(r_{t}-p_{t}\right)+\varepsilon_{r p, t+1},
\end{aligned}
$$

which we estimate using ordinary least squares. We evaluate the significance of $b_{h}$ and $b_{r}$ in two ways. First, we use standard $t$-tests based on asymptotic standard errors. To account for possible serial correlation and heteroskedasticity in the error terms, we use the standard errors by Newey and West (1987). The usual $t$-test is marginal in the sense that return and rent growth predictability are tested in isolation. However, the present value relation (2) shows that if, for example, the rent-price ratio does not predict future returns, then it must predict future rent growth. In other words, since the rent-price ratio varies over time then either expected returns or expected rent growth, or both, must also vary over time, i.e. we cannot have a null hypothesis in which we both have unpredictable returns and unpredictable rent growth. We exploit this relation to construct a joint test, which has higher power than the usual marginal test, i.e. the joint test is more likely to reject the null hypothesis of no predictability when predictability is actually present than the marginal test. This idea has also been applied in the literature on stock return and dividend growth predictability by the dividend-price ratio, see e.g. Cochrane (2008) and Engsted and Pedersen (2010). Plazzi et al. (2010) also exploit the present value relation (2) in an analysis of return and rent growth predictability by the rent-price ratio in the US real estate market. However, rather than constructing joint tests they estimate the predictive regressions using Generalized Method of Moments while imposing the present value restriction.

The joint test directly exploits the connection between return, rent growth, and the rent-price ratio given by the approximate identity (1). Given the system (4)-(6), equation (1) links the regression coefficients of the VAR, and hence by projecting on the rent-price ratio, we get the following approximate identity between the regression coefficients

$$
b_{h}=1-\rho \phi+b_{r}
$$


Furthermore, the VAR errors are also linked by the approximate identity

$$
\varepsilon_{h, t+1}=\varepsilon_{r, t+1}-\rho \varepsilon_{r p, t+1}
$$

This implies that we can infer the data, coefficients, and errors of any one equation from those of the other two. It also means that when we want to test, say, $b_{h}=0$, we have to change the rent growth coefficient $b_{r}$ or the rent-price ratio autocorrelation coefficient $\phi$ accordingly.

In testing these joint hypotheses we follow Cochrane (2008) and simulate data under the respective nulls, and thereby test the hypotheses using simulated small-sample distributions. We test a null of no return predictability $\left(b_{h}=0\right)$ and a null of no rent growth predictability $\left(b_{r}=0\right)$. In both cases we use the estimated rent-price ratio autocorrelation coefficient, $\widehat{\phi}$, and calculate the rent growth coefficient $b_{r}$ and return coefficient $b_{h}$, respectively, using (7).

When simulating data under the respective nulls we have to choose two variables to simulate and let the third follow from the approximate identity (1). We simulate the rent-price ratio and the variable which is predictable under the null, i.e. under the null of no return predictability we simulate rent growth, and under the null of no rent growth predictability we simulate returns. We randomly draw $\varepsilon_{r p, t}$ and $\varepsilon_{r, t}$ or $\varepsilon_{h, t}$, depending on the null hypothesis, from the residuals. The first observation $r_{0}-p_{0}$ is drawn randomly from the observed rent-price ratios and then the VAR system is simulated forward. We simulate the system 10,000 times, and for each simulation we estimate (4)-(5) and collect the coefficients.

According to the present value relation (2) the rent-price ratio should predict returns with a positive sign and rent growth with a negative sign. In calculating the simulated joint p-value we could use this insight and for the null hypothesis of no return predictability report the simulated joint probability that the coefficients are larger than their sample values, $P\left(b_{h}>\widehat{b}_{h}\right.$ and $\left.b_{r}>\widehat{b}_{r}\right)$, and for the null hypothesis of no rent growth predictability report the simulated joint probability that the coefficients are smaller than their sample values, $P\left(b_{h}<\widehat{b}_{h}\right.$ and $\left.b_{r}<\widehat{b}_{r}\right)$. However, as we shall see later, in some cases the signs of the estimated predictive coefficients are 'wrong', i.e. opposite to what is expected according to $(2)$. For example, $\widehat{b}_{h}$ is in a few cases estimated to be negative. To accommodate predictive coefficients of the 'wrong' sign we will instead report the probability of the upper one-sided alternative, $P\left(b_{h}>\widehat{b}_{h}\right.$ and $\left.b_{r}>\widehat{b}_{r}\right)$, if the estimated predictive coefficient is positive and the probability of the lower one-sided alternative, 
$P\left(b_{h}<\widehat{b}_{h}\right.$ and $\left.b_{r}<\widehat{b}_{r}\right)$, if the coefficient is negative. Hence, we get simulated p-values that can be interpreted in the usual way, where a p-value smaller than a chosen significance level implies that we reject the null hypothesis against the relevant one-sided alternative, i.e. if the predictive coefficient is positive (negative) and we reject the null hypothesis we conclude that the rent-price ratio has positive (negative) predictive power of either returns or rent growth depending on the null hypothesis.

In a robustness and sub-sample analysis we use the quarterly dataset. To account for remaining seasonality in the data we in this case use a restricted fourth-order VAR model

$$
\begin{aligned}
h_{t+1} & =a_{h}+\sum_{i=1}^{4} b_{h, i}\left(r_{t+1-i}-p_{t+1-i}\right)+\varepsilon_{h, t+1}, \\
\Delta r_{t+1} & =a_{r}+\sum_{i=1}^{4} b_{r, i}\left(r_{t+1-i}-p_{t+1-i}\right)+\varepsilon_{r, t+1}, \\
r_{t+1}-p_{t+1} & =a_{r p}+\sum_{i=1}^{4} \phi_{i}\left(r_{t+1-i}-p_{t+1-i}\right)+\varepsilon_{r p, t+1} .
\end{aligned}
$$

As one overall measure of predictability we report the sum of the coefficients and calculate the associated Newey-West standard errors using the delta method. We also construct joint tests. Projecting on four lags of the rent-price ratio, the approximate identity (1) yields the following links between the regression coefficients

$$
\left[\begin{array}{c}
\beta_{h, 1} \\
\beta_{h, 2} \\
\beta_{h, 3} \\
\beta_{h, 4}
\end{array}\right]=\left[\begin{array}{l}
\beta_{r, 1} \\
\beta_{r, 2} \\
\beta_{r, 3} \\
\beta_{r, 4}
\end{array}\right]+\left[\begin{array}{l}
1 \\
0 \\
0 \\
0
\end{array}\right]-\rho\left[\begin{array}{l}
\phi_{1} \\
\phi_{2} \\
\phi_{3} \\
\phi_{4}
\end{array}\right] .
$$

We use the same simulation setup as with annual data to construct the joint tests. The autoregressive coefficients for the rent-price ratio are set equal to their estimated values and under the null hypothesis of no return predictability we set $b_{h, i}=0$ for all $i$ and calculate the corresponding coefficients for the rent growth regression using (12). Likewise under the null hypothesis of no rent growth predictability. The initial four values of the rent-price ratio are drawn randomly from the observed rent-price ratios in blocks of four. Our joint test is based on the sum of the coefficients such that the p-value under the null of no predictability is calculated as $P\left(\sum_{i=1}^{4} b_{h, i}>\sum_{i=1}^{4} \widehat{b}_{h, i}\right.$ and $\left.\sum_{i=1}^{4} b_{r, i}>\sum_{i=1}^{4} \widehat{b}_{r, i}\right)$ if the sum of the predictive coefficients is positive and as $P\left(\sum_{i=1}^{4} b_{h, i}<\sum_{i=1}^{4} \widehat{b}_{h, i}\right.$ and 
$\left.\sum_{i=1}^{4} b_{r, i}>\sum_{i=1}^{4} \widehat{b}_{r, i}\right)$ if the sum of the coefficients is negative.

\section{Empirical results}

\subsection{Predicting nominal returns and rent growth}

Table 2 shows the results for return and rent growth predictability using nominal data. Focusing first on return predictability we observe that for all countries except Japan, Germany, and Switzerland the sign of $\widehat{b}_{h}$ is positive as expected from the present value relation (2). Among the countries with a positive $\widehat{b}_{h}$ Belgium, France, Sweden, and US stand out since the marginal $t$-test for these countries does not indicate significant predictability. For the remaining countries the $t$-statistic is above 2 which implies that returns on the real estate market are significantly predictable by the rent-price ratio on a $5 \%$ level. The $R^{2}$ is for many countries also remarkably high. For example, in Spain and Ireland the $R^{2}$ is $49.8 \%$ and $40.0 \%$, respectively.

Although we in some cases are not able to reject the null hypothesis of no return predictability using the marginal $t$-test, we might reach a different conclusion using the more powerful joint test. This is the case for Belgium, France, and Sweden. The p-value based on the joint test is here below $5 \%$ which implies that returns are predictable by the rent-price ratio also in these countries. The parameter values under the null hypotheses used in the joint tests are shown in Table 3. As an example consider Sweden. Under the null hypothesis of no return predictability $b_{h}=0$ and with $\rho=0.956$ and $\widehat{\phi}=0.931$ we use $(7)$ to calculate that $b_{r}$ should be equal to -0.110 . That is, under the null hypothesis of no return predictability we must have negative rent growth predictability by the rentprice ratio of a certain magnitude. Using the parameter values under the null hypothesis we simulate data and estimate $b_{h}$ and $b_{r}$. The p-value is then calculated as the fraction of simulations where the parameter values based on simulated data are larger than the estimated parameter values reported in Table 2. For Sweden $\widehat{b}_{r}=-0.059$ but this it not sufficiently negative to make $b_{h}=0$ plausible. In fact, only in $1.3 \%$ of the simulations do we obtain values of $b_{h}$ and $b_{r}$ that are jointly larger than the estimated values reported in Table 2. Figure $1 \mathrm{~A}$ in the appendix displays the simulated p-value graphically for all countries using nominal data.

In conflict with the a priori expectation based on (2) the sign of $\widehat{b}_{h}$ is negative but insignificant based on the marginal $t$-test for Japan, Germany, and Switzerland. However, 
using the more powerful joint test we find strong evidence that the rent-price ratio predicts returns with a negative sign in Japan and Germany. For Switzerland the predictive return coefficient is marginally significant.

Turning to rent growth we find that $\widehat{b}_{r}$ is negative for seven out of 18 countries, in accordance with the present value relation (2). For six of these countries $b_{r}$ is significantly negative: Japan, Germany, Switzerland, Italy, Sweden, and US. Note, for the latter three countries we need the joint test to conclude predictability. For some countries we find a remarkably high degree of explanatory power by the rent-price ratio. For example, for Germany and Switzerland the $R^{2}$ is close to $50 \%$. For the remaining 11 countries Table 2 shows that on a $5 \%$ level $\widehat{b}_{r}$ is significantly positive for Australia, Belgium, Canada, Spain, Norway, and New Zealand.

Summing up, based on the simulated p-value we arrive at the following conclusions. Nominal returns on the real estate market are significantly predictable by the rent-price ratio with a positive sign in all countries except US, Japan, Germany, and Switzerland. In conflict with the present value relation (2) nominal returns are (significantly) predictable with a negative sign in Japan, Germany, and Switzerland. Nominal rent growth is significantly predictable with a negative sign in Japan, Germany, Switzerland, Italy, Sweden, and US, and unpredictable in Denmark, Finland, France, UK, Ireland, and Holland. For the remaning six countries nominal rent growth is significantly predictable with a positive sign in conflict with the present value relation (2).

\subsection{Predicting real returns and rent growth}

The conclusions using nominal data do not in general carry over to real data as seen by comparing the results in Table 2 to those in Table 4. For returns a noticeable difference is that the negative and (close to) significant coefficient for Japan, Germany, and Switzerland using nominal data turns positive using real data. In fact, for Switzerland the coefficient is now significantly positive as seen from the simulated joint p-value. ${ }^{6}$ This difference can only be explained by the fact that the rent-price ratio predicts inflation with a negative sign in these countries. From the present value relation (3) it is clear that a negative return coefficient using nominal data can only turn positive if the inflation coefficient is negative and numerically larger than the return coefficient. Table 5 confirms

\footnotetext{
${ }^{6}$ The parameter values under the null hypotheses are the same using nominal and real data. The parameter values are determined by the first-order autocorrelation coefficient for the rent-price ratio and the linearization constant $\rho=e^{E[\Delta r-h]}$, both of which are not affected by inflation. The simulated data will however be different since the randomly drawn $\varepsilon_{r, t}$ and $\varepsilon_{h, t}$ are different for nominal and real data.
} 
that the rent-price ratio predicts inflation with a negative sign in Japan, Germany, and Switzerland. In the latter two countries this predictability is highly significant and the $R^{2}$ is around $40 \%$.

Another country in which the rent-price ratio predicts inflation with a negative sign is the US. Using nominal data we do not find that returns on the real estate market in this country are significantly predictable by the rent-price ratio, cf. Table 2, but for real data returns are highly signficantly predictable, cf. Table 4. Again the explanation of this discrepancy is that inflation is negatively predictable by the rent-price ratio.

The interesting implication of these findings is that the apparent strong predictability of real estate returns in Switzerland and the US is an artifact of inflation predictability by the rent-price ratio. Note, these differences in conclusions using nominal and real data do not require inflation to be significantly predictable by the rent-price ratio. The last country for which inflation is negatively predictable by the rent-price ratio is Sweden. Since nominal returns already are predictable in Sweden the consequence of this negative predictability is to reinforce real return predictability by the rent-price ratio.

For the remaining 14 countries the inflation coefficient is positive. For some countries (Australia, Canada, Spain, Finland, and Ireland) inflation is strongly predictable by the rent-price ratio. For example, in Spain the $R^{2}$ is close to $60 \%$. The size of the inflation coefficient is also relatively large in these countries, which implies that we might find a discrepancy between the results using nominal and real data. In contrast, in countries like Belgium, Denmark, UK, and Holland we find no significant inflation predictability by the rent-price ratio and the inflation coefficient is close to zero. Hence, for these countries we would expect to arrive at the same conclusion irrespective of the use of nominal or real data. Nominal returns are significantly predictable with a positive sign in these 14 countries, cf. Table 2. The consequence of positive inflation predictability is to reduce this predictability in real terms as also seen from the present value relation (3). From Table 4 we see that although the return coefficients and the $R^{2}$ 's decrease from nominal to real data, the degree of inflation predictability is not strong enough to overturn the conclusion that returns are significantly predictable in these 14 countries.

Turning to rent growth we first consider the five countries for which the inflation coefficient is negative, i.e. Japan, Germany, Switzerland, Sweden, and US. Table 2 shows that nominal rent growth is negatively predictable by the rent-price ratio in these countries. The effect of the negative inflation coefficient is reduced real rent growth predictability as seen by comparing Tables 2 and 4 . This can again be explained using the 
present value relation (3). For some of these countries the degree of inflation predictability renders real rent growth unpredictable. This is the case for Germany, US, and Japan. In fact, for Japan the real rent growth coefficient turns positive (but insignificant). For Switzerland and Sweden rent growth remains negatively predictable by the rent-price ratio also using real data. Although we reject the null hypothesis of no real rent growth predictability for these two countries, the degree of predictability has clearly decreased compared to the case with nominal data. For example, for Switzerland the $R^{2}$ goes from close to $50 \%$ using nominal data to $4 \%$ using real data.

For the remaining 13 countries the inflation coefficient is estimated to be positive. Two of these countries (Ireland and Italy) display negative nominal rent growth predictability, cf. Table 2, and in combination with the positive inflation coefficient this leads to a reinforcement of negative rent growth predictability using real data. For Ireland the rent growth coefficient goes from insignificant to significant and the $R^{2}$ increases from

$0.07 \%$ to $10.8 \%$. For the other countries $\widehat{b}_{r}$ using nominal data is estimated to be positive but for many countries the degree of inflation predictability by the rent-price ratio is so strong that $\widehat{b}_{r}$ using real data is estimated to be significantly negative. This is the case for Australia, Canada, Spain, Finland, France, and Norway.

In conclusion we find that the degree of return and rent growth predictability by the rent-price ratio can be very different depending on the use of nominal or real data, and that the explanation of this discrepancy is inflation predictability by the rent-price ratio. For Japan, Germany, and Switzerland the degree of inflation predictability is able to switch sign of the return coefficient from nominal to real data. For the latter country inflation predictability even makes the real return coefficient significantly positive, in contrast to the nominal case where the coefficient is (borderline) significantly negative. Also for the US inflation predictability has an effect on the conclusion about return predictability. Using nominal data the return coefficient is not significant while for real data it is strongly significantly positive. Also for rent growth we find that inflation predictability by the rent-price ratio can change the sign of the predictive coefficient and the conclusion in terms of statistical significance.

\subsection{Sub-sample analysis}

Figures 1 and 2 indicate that the relation between the rent-price ratio and returns and rent growth, respectively, might not be constant over time. As also mentioned in section 2 for most countries prices appear to have been disconnected from rents since the mid 
1990s. To evaluate if the predictability patterns by the rent-price ratio are different in calm periods and periods with turbulence on the real estate market we in this section make a sub-sample analysis. Motivated by the apparent changes in the relation between prices and rent in the mid 1990s we consider the two sample periods 1970-1994 and 19952011. The first sample period is generally characterized by slowly increasing prices and rents, while the second contains both dramatic increases and decreases in prices, which in turn are not mirrored in rents.

Due to the limited number of annual observations in these two sample periods, we opt to use quarterly data in the sub-sample analysis. To ensure that the results are not influenced (at least to a great extent) by the change in data frequency, we first conduct a robustness analysis of the full sample results using quarterly data. As mentioned in section 3.2 we use a restricted fourth-order VAR model in this case with the aim of eliminating potential serial correlation in the residuals due to seasonality.

Tables 6 and 7 contain the full-sample results using nominal and real data, respectively. In general, compared to annual data we find noticeable differences in the predictive coefficient, the $R^{2}$ and the $t$-statistic. These differences are not surprising given the difference in data frequency. For our purpose what is important is if the predictive coefficients have the same sign and the simulated joint p-values yield the same conclusions across data frequency. We generally find this to be the case. In a few cases there is a discrepancy between the results using annual and quarterly data. Using nominal data the predictive coefficients change sign for Japan (returns) and Ireland (rent growth). However, for the latter country the conclusion based on the simulated joint p-value remains, i.e. we cannot reject the null hypothesis of no rent growth predictability. For Japan we conclude that $b_{h}$ is significantly negative using annual data while the use of quarterly data implies that we cannot reject the null hypothesis of no return predictability. In all other cases the sign of the predictive coefficients remain. In a couple of cases we obtain different conclusions. For example, using quarterly data we now find evidence of nominal return predictability in the US and real return predictability in Japan. However, generally the annual and quarterly dataset yield the same conclusions in terms significant return and rent growth predictability.

Tables 8 and 9 show for nominal and real data, respectively, the estimated predictive coefficients and simulated joint p-values before and after 1995. For brevity we do not report $R^{2}$ and $t$-statistics. Our focus is on changes in significant predictability across the two sample periods, which can be evaluated using only the predictive coefficients and the simulated joint p-value. 
For most countries the return predictability (using both nominal and real returns) found using the full sample is also present both before and after 1995. However, for some countries we find noticeable differences across the two sample periods. For example, there is no evidence of nominal return predictability in France and Sweden in the first sample period, but in the second sample period we strongly reject the null hypothesis of no return predictability against the upper one-sided alternative. For the US we find similar results with the exception that we in the first sample period strongly reject the null hypothesis of no return predictability against the lower one-sided alternative, i.e. nominal returns in the US are significantly predictable by the rent-price ratio with a negative sign in the period 1970-1994 and with a positive sign in the period 1995-2011. For Japan we find that returns (both nominal and real) are predictable in the first sample period but not the second, i.e. the rent-price ratio had predictive power when prices increased dramatically in Japan, but not during the period with decreasing prices. These differences across sub-samples are not in direct conflict with the full-sample results. This is, however, the case for nominal returns in Switzerland and Germany. Using the full sample the return coefficient is negative in these two countries (and in fact for Germany significantly so), but Table 8 shows that it is significantly positive in both sub-samples.

For rent growth we also find sub-sample results, which are in conflict with those based on the full sample, and in general we see a larger degree of sub-sample difference compared to returns. Beginning with nominal rent growth we found in the full sample that the predictive coefficient was (significantly) negative in six countries. Table 8 shows that this result is not robust across sub-samples. For Switzerland, Italy, Sweden, and US the significant negative predictability is only present in the first sample period, while for Germany and Japan it is only there in the second sample period. Although the rent growth coefficient is positive over the full sample period for the 12 other countries, Table 8 shows that it is significantly negative in at least one sub-period for all countries except Spain. Australia, Canada, Finland, and Ireland all have negative rent growth predictability in the second sample period, but not the first, while the opposite is the case for Belgium, UK, Holland, and Norway. The remaining three countries stand out since rent growth is predictable with a negative sign in both sub-samples, but not in the full sample.

Using real rent growth we find similar differences across the sample periods. Among the countries with significant negative predictability over the full sample we find that this holds across both sub-samples for only Canada and Ireland. For the other countries with significant negative predictability over the full sample we find that this is only 
present in one of the sub-samples (and in the case of Norway in neither of the subsamples). Similar to the case with nominal data we do not observe a general pattern here; some countries experience rent growth predictability in the first sub-sample and others in the second. Also, countries where the predictive coefficient is insignificant over the full sample experience significant negative predictability in one sub-sample period. The only countries where the rent growth coefficient never becomes significantly negative are Denmark, UK, Japan, and Holland.

Overall, the sub-sample results show that for most countries the rent-price ratio predicts returns with a positive sign in both calm and turbulent periods. Only France, Japan, Sweden, and US have experienced some instability in this relation, and not in a coherent way. In contrast, rent growth predictability is very sensitive to the sample period. In addition to the obvious changes in the relation between prices and rents due to the dramatic increase in prices in the mid 1990s this could also be due to structural changes in the rental market over time. Tables 8 and 9 also show that for some countries the sub-sample differences in rent growth predictability are not robust to the use of nominal and real data, which indicates that inflation predictability by the rent-price ratio changes over time for these countries.

\subsection{Further robustness analysis}

In this section we report briefly on robustness analyses we have done in the form of $i$ ) long-horizon regressions, and $i i$ ) correction for small-sample bias.

\subsubsection{Long-horizon predictability}

In this paper we have focused on short-term (one-period ahead) predictability by using the regressions (4)-(6). From the regression estimates and the identity (7), long-horizon $(k$-period ahead) coefficients can be inferred as

$$
b_{h}^{(k)}=\frac{1-\rho^{k} \phi^{k}}{1-\rho \phi} b_{h}, \quad b_{r}^{(k)}=\frac{1-\rho^{k} \phi^{k}}{1-\rho \phi} b_{r}
$$

These $k$-period coefficients measure the fraction of the variance of the rent-price ratio that can be attributed to time-varying $k$-horizon expected returns and rent growth, respectively (cf. Cochrane, 2008, and Engsted and Pedersen, 2010). Naturally, this inter- 
pretation assumes that the first-order system (4)-(6) captures well the actual long-horizon behavior of the variables.

As a robustness check we have run regressions of actual $k$-period returns and rent growth onto the log rent-price ratio, with $k$ up to 5 years. In general, the results are qualitatively very similar to those we have reported for $k=1$ in Tables 2 and 4 , so to save space we do not report these results here (but details are available upon request). This implies that the results we have reported with $k=1$ in fact also describe well longer-horizon predictability by the rent-price ratio.

\subsubsection{Small-sample bias}

It is well-known that the OLS estimates of $b_{h}, b_{r}$, and $\phi$ in (4)-(6) are plagued with small-sample bias which can seriously distort statistical inference on these parameters, especially if the predictor variable is highly persistent, cf. Stambaugh (1999). Kendall (1954) derived the small-sample bias of the $\operatorname{AR}(1)$ coefficient $\widehat{\phi}$ in (6), and through the correlations of the innovations in (6) with the innovations in (4) and (5), this bias translates into a bias in $\widehat{b}_{h}$ and $\widehat{b}_{r}$.

In the simulated joint tests reported in Tables 2,4 , and 6-9 (the $P_{S}$ values), we automatically account for the part of this small-sample bias that stems from the innovation correlations. However, these joint tests do not account for the part of the bias that comes from the downward biased OLS estimate of $\phi$. In order to check the robustness of our results wrt. this bias, we have adjusted the OLS estimate of $\phi$ for bias using Kendall's (1954) formula and used this adjusted estimate to calculate parameter values under the null hypotheses as in Table 3 and in simulating data. In general the conclusions from sections 4.1 and 4.2 continue to hold, except in a few cases, so for brevity the results are not shown (but are available upon request).

\section{Concluding remarks}

In the majority of OECD countries house prices rose dramatically up to around 2006, whereafter prices either stabilized or dropped. Thus, there was a clear comovement in international real estate markets. From this one might conjecture that there should also be a common pattern in the predictability of real estate markets across countries. However, in this paper we have shown that this is not the case. 
Based on the dynamic Gordon growth model, in which the rent-price ratio summarizes market expectations of future real estate returns and rent growth, we have documented strong cross-country differences in the rent-price ratio's predictive power for returns and rent growth. In the majority of countries the ratio positively predicts returns in accordance with the model, but with respect to rent growth the cross-country differencese are very pronounced: For one large group of countries the rent-price ratio significantly predicts rent growth with a negative coefficient, while for another large group of countries the rent-price ratio significantly predicts rent growth with a positive coefficient.

Furthermore, we have documented that for many countries the predictability patterns are strongly dependent on whether returns and rents are measured in nominal or real terms, especially when it comes to rent growth predictability. In many cases nominal rent growth predictability with a positive rent-price coefficient is turned into real rent growth predictability with a negative rent-price coefficient. The explanation for this is that inflation turns out to be predictable by the rent-price ratio. Thus, when examining predictability in real estate markets it is crucially important whether prices and rents are measured in nominal or real terms. We have also documented some sub-sample instability in the predictability patterns. In a number of countries predictability results on samples after 1994 are different from the results on samples up to 1994.

These cross-country differences, differences in the predictability of nominal and real variables, and the sub-sample instabilities, imply that there is not one common coherent interpretation of the price movements we have experienced in international real estate markets. In order to fully understand the underlying causes for the price movements one needs to investigate in more detail the specific conditions and institutional settings (e.g. the regulation of rental markets) in each individual country. We leave that for future research. We also leave for future research the question of why the rent-price ratio appears to predict future inflation. As we have seen this is the key to understanding the differences between predicting nominal and real returns and rents. Interestingly, the same phenomenon has been observed in the stock market where the dividend-price ratio appears to be a powerful predictor of future inflation (Engsted and Pedersen, 2010). Thus, also in this respect there are interesting similarities between equity and real estate markets, similarities that call for further scrutiny in future research. 


\section{References}

[1] Campbell, D., Morris, D., Gallin, J., and Martin, R. (2009). What moves housing markets: A variance decomposition of the rent-price ratio. Journal of Urban Economics 66, 90-102.

[2] Campbell, J.Y. and Shiller, R.J. (1988). The dividend-price ratio and expectations of future dividends and discount factors. Review of Financial Studies 1, 195-228.

[3] Case, K.E. and Shiller, R.J. (1989). The efficiency of the market for single-family homes. American Economic Review 79, 125-137.

[4] Cochrane, J.H. (2008). The dog that did not bark. A defense of return predictability. Review of Financial Studies 21, 1533-1575.

[5] Cochrane, J.H. (2011). Discount rates (Presidential address). Journal of Finance 66, 1047-1108.

[6] Engsted, T. and Pedersen, T.Q. (2010). The dividend-price ratio does predict dividend growth: International evidence. Journal of Empirical Finance 17, 585-605.

[7] Engsted, T., Pedersen, T.Q., and Tanggaard, C. (2012). The log-linear return approximation, bubbles, and predictability. Journal of Financial and Quantitative Analysis 47, 643-665.

[8] Gallin, J. (2008). The long-run relationship between house prices and rents. Real Estate Economics 36, 635-658.

[9] Ghysels, E., Plazzi, A., Torous, W., and Valkanov, R. (2012). Forecasting real estate prices. Forthcoming in: Elliott, G. and A. Timmermann (Eds.), Handbook of Economic Forecasting 2.

[10] Girouard, N., Kennedy, M., van den Noord, P., and André, C. (2006). Recent house price developments: The role of fundamentals. OECD Economics Department Working Paper no. 475.

[11] Hardouvelis, G.A. (1994). The term structure spread and future changes in long and short rates in the G7 countries: Is there a puzzle? Journal of Monetary Economics $33,255-283$.

[12] Himmelberg, C., Mayer, C., and Sinai, T. (2005). Assessing high house prices: Bubbles, fundamentals and misperceptions. Journal of Economic Perspectives 19, 67-92. 
[13] Kendall, M.G. (1954). Note on bias in the estimation of autocorrelation. Biometrica 41, 403-404.

[14] Newey, W.K. and West, K.D. (1987). A simple positive semi-definite, heteroscedasticity and autocorrelation consistent covariance matrix. Econometrica 55, 703-708.

[15] Plazzi, A., Torous, W., and Valkanov, R. (2010). Expected returns and expected growth in rents of commercial real estate. Review of Financial Studies 23, 34693519.

[16] Shiller, R.J. (2005). Irrational Exuberance (2nd edition). Princeton University Press, Princeton and Oxford.

[17] Stambaugh, R. (1999). Predictive regressions. Journal of Financial Economics 54, 375-421. 
Figure 1. Time-series plot of real house prices and rents
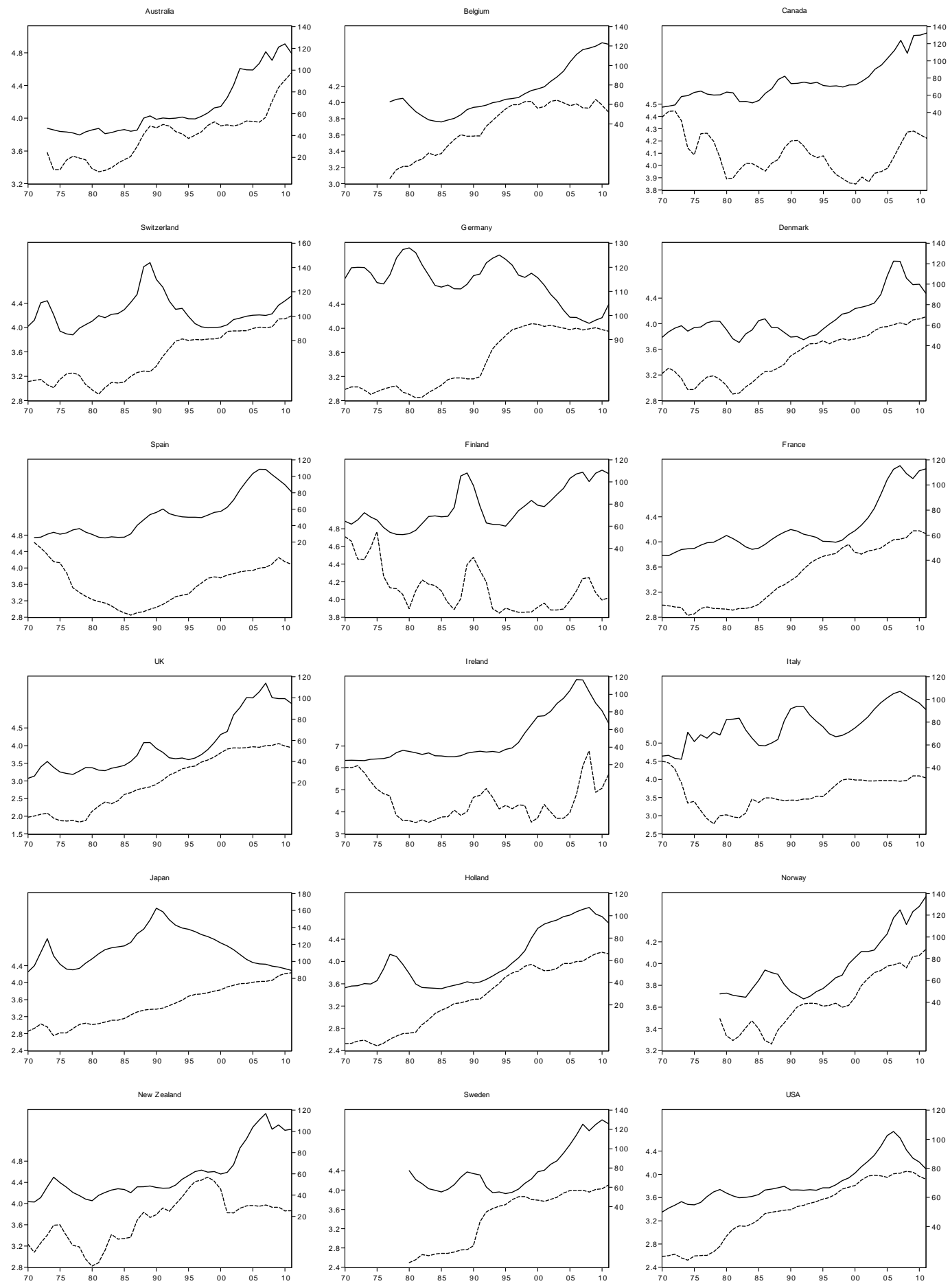

Notes: The solid line (right axis) gives the (indexed) house price and the dotted line (left axis) gives the (indexed) rent. 
Figure 2. Time-series plot of the rent-to-price ratio
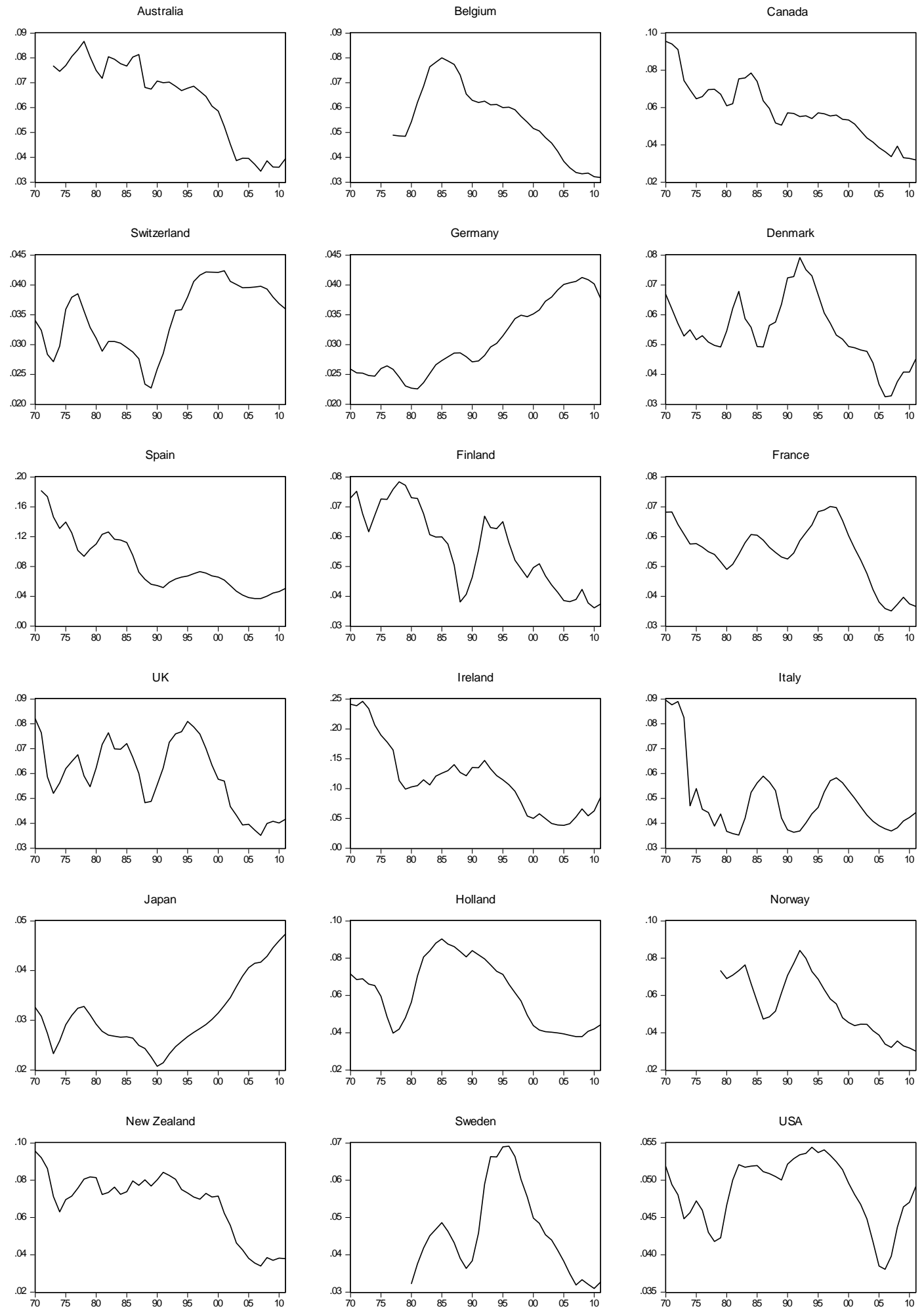
Table 1. Descriptive statistics

\begin{tabular}{|c|c|c|c|c|c|c|c|c|c|}
\hline & \multicolumn{9}{|c|}{ Panel A: Nominal return, rent growth, and price growth } \\
\hline & \multicolumn{3}{|c|}{ Return } & \multicolumn{3}{|c|}{ Rent growth } & \multicolumn{3}{|c|}{ Price growth } \\
\hline & $\mu$ & $\sigma$ & $\phi(1)$ & $\mu$ & $\sigma$ & $\phi(1)$ & $\mu$ & $\sigma$ & $\phi(1)$ \\
\hline Australia & 0.156 & 0.086 & 0.297 & 0.062 & 0.041 & 0.875 & 0.082 & 0.073 & 0.182 \\
\hline Belgium & 0.113 & 0.049 & 0.574 & 0.038 & 0.024 & 0.848 & 0.051 & 0.043 & 0.652 \\
\hline Canada & 0.135 & 0.089 & 0.277 & 0.042 & 0.032 & 0.862 & 0.073 & 0.081 & 0.186 \\
\hline Switzerland & 0.070 & 0.066 & 0.546 & 0.034 & 0.030 & 0.720 & 0.035 & 0.067 & 0.563 \\
\hline Germany & 0.056 & 0.034 & 0.782 & 0.034 & 0.024 & 0.833 & 0.025 & 0.036 & 0.796 \\
\hline Denmark & 0.123 & 0.095 & 0.483 & 0.052 & 0.032 & 0.888 & 0.066 & 0.091 & 0.471 \\
\hline Spain & 0.203 & 0.142 & 0.756 & 0.073 & 0.037 & 0.921 & 0.113 & 0.116 & 0.657 \\
\hline Finland & 0.131 & 0.108 & 0.545 & 0.051 & 0.057 & 0.643 & 0.071 & 0.102 & 0.503 \\
\hline France & 0.131 & 0.064 & 0.776 & 0.055 & 0.038 & 0.958 & 0.072 & 0.062 & 0.764 \\
\hline UK & 0.166 & 0.112 & 0.496 & 0.079 & 0.060 & 0.739 & 0.101 & 0.106 & 0.464 \\
\hline Ireland & 0.216 & 0.146 & 0.874 & 0.065 & 0.113 & 0.170 & 0.092 & 0.111 & 0.784 \\
\hline Italy & 0.153 & 0.167 & 0.189 & 0.074 & 0.062 & 0.683 & 0.100 & 0.161 & 0.161 \\
\hline Japan & 0.058 & 0.081 & 0.707 & 0.034 & 0.038 & 0.951 & 0.027 & 0.081 & 0.720 \\
\hline Holland & 0.128 & 0.100 & 0.721 & 0.048 & 0.026 & 0.864 & 0.064 & 0.095 & 0.711 \\
\hline Norway & 0.135 & 0.087 & 0.489 & 0.045 & 0.029 & 0.864 & 0.077 & 0.085 & 0.482 \\
\hline New Zealand & 0.170 & 0.102 & 0.587 & 0.070 & 0.067 & 0.754 & 0.096 & 0.093 & 0.528 \\
\hline Sweden & 0.104 & 0.069 & 0.492 & 0.057 & 0.056 & 0.667 & 0.058 & 0.068 & 0.482 \\
\hline USA & 0.102 & 0.046 & 0.834 & 0.050 & 0.035 & 0.830 & 0.052 & 0.045 & 0.828 \\
\hline
\end{tabular}

Continues on next page 


\begin{tabular}{|c|c|c|c|c|c|c|}
\hline & \multicolumn{6}{|c|}{ Panel C: Inflation and the rent-to-price ratio } \\
\hline & \multicolumn{3}{|c|}{ Inflation } & \multicolumn{3}{|c|}{$\mathrm{R} / \mathrm{P}$} \\
\hline & $\mu$ & $\sigma$ & $\phi(1)$ & $\mu$ & $\sigma$ & $\phi(1)$ \\
\hline Australia & 0.057 & 0.043 & 0.876 & 0.064 & 0.017 & 0.993 \\
\hline Belgium & 0.031 & 0.021 & 0.698 & 0.055 & 0.015 & 1.012 \\
\hline Canada & 0.043 & 0.035 & 0.890 & 0.058 & 0.016 & 0.921 \\
\hline Switzerland & 0.027 & 0.027 & 0.770 & 0.035 & 0.006 & 0.930 \\
\hline Germany & 0.027 & 0.022 & 0.774 & 0.031 & 0.006 & 0.998 \\
\hline Denmark & 0.046 & 0.038 & 0.884 & 0.054 & 0.011 & 0.915 \\
\hline Spain & 0.077 & 0.060 & 0.901 & 0.083 & 0.038 & 0.896 \\
\hline Finland & 0.054 & 0.049 & 0.734 & 0.056 & 0.013 & 0.942 \\
\hline France & 0.047 & 0.043 & 0.910 & 0.055 & 0.010 & 0.980 \\
\hline UK & 0.061 & 0.054 & 0.853 & 0.060 & 0.014 & 0.892 \\
\hline Ireland & 0.062 & 0.063 & 0.869 & 0.116 & 0.059 & 0.919 \\
\hline Italy & 0.077 & 0.064 & 0.842 & 0.049 & 0.014 & 0.784 \\
\hline Japan & 0.024 & 0.048 & 0.758 & 0.031 & 0.007 & 1.050 \\
\hline Holland & 0.035 & 0.028 & 0.810 & 0.061 & 0.018 & 0.972 \\
\hline Norway & 0.040 & 0.032 & 0.821 & 0.055 & 0.016 & 0.969 \\
\hline New Zealand & 0.065 & 0.060 & 0.762 & 0.068 & 0.017 & 0.966 \\
\hline Sweden & 0.043 & 0.038 & 0.789 & 0.046 & 0.012 & 0.934 \\
\hline USA & 0.039 & 0.026 & 0.797 & 0.048 & 0.004 & 0.909 \\
\hline
\end{tabular}

Notes: $\mu$ is the mean, $\sigma$ standard deviation, and $\phi(1)$ the first-order autocorrelation coefficient. The sample period begins in 1970 for all countries except Australia (1973), Belgium (1977), Spain, (1971), Normay (1979), and Sweden (1980). The sample period ends in 2011 for all countries. Data are annual. 
Table 2. Return and rent growth predictability using nominal data

\begin{tabular}{|c|c|c|c|c|c|c|c|c|}
\hline & \multicolumn{4}{|c|}{ Returns } & \multicolumn{4}{|c|}{ Rent growth } \\
\hline & $\widehat{b}_{h}$ & $t_{N W}$ & $P_{S}$ & $R^{2}$ & $\widehat{b}_{r}$ & $t_{N W}$ & $P_{S}$ & $R^{2}$ \\
\hline Australia & 0.108 & 3.89 & 0.05 & 20.87 & 0.054 & 2.19 & 4.03 & 17.18 \\
\hline Belgium & 0.049 & 1.61 & 0.01 & 10.38 & 0.032 & 3.10 & 0.24 & 13.80 \\
\hline Canada & 0.131 & 3.48 & 0.01 & 21.30 & 0.050 & 3.90 & 2.69 & 19.14 \\
\hline Switzerland & -0.010 & -0.17 & 5.20 & 0.08 & -0.119 & -5.07 & 0.00 & 49.69 \\
\hline Germany & -0.047 & -1.23 & 0.40 & 7.92 & -0.081 & -6.34 & 0.07 & 46.07 \\
\hline Denmark & 0.156 & 2.06 & 0.01 & 15.38 & 0.030 & 0.96 & 13.86 & 4.66 \\
\hline Spain & 0.181 & 5.22 & 0.00 & 49.77 & 0.049 & 3.86 & 1.32 & 42.19 \\
\hline Finland & 0.152 & 3.67 & 0.05 & 15.39 & 0.050 & 1.32 & 8.50 & 5.33 \\
\hline France & 0.071 & 1.06 & 2.63 & 5.67 & 0.018 & 0.43 & 26.55 & 0.98 \\
\hline UK & 0.174 & 3.00 & 0.00 & 20.66 & 0.041 & 1.11 & 6.44 & 3.45 \\
\hline Ireland & 0.146 & 3.39 & 0.03 & 39.87 & -0.005 & -0.18 & 11.50 & 0.07 \\
\hline Italy & 0.195 & 2.01 & 0.00 & 15.60 & -0.054 & -1.26 & 3.40 & 5.95 \\
\hline Japan & -0.053 & -0.99 & 0.10 & 2.27 & -0.065 & -2.15 & 0.11 & 13.24 \\
\hline Holland & 0.105 & 2.92 & 0.01 & 13.53 & 0.019 & 1.04 & 17.97 & 5.55 \\
\hline Norway & 0.081 & 2.01 & 0.00 & 9.73 & 0.029 & 1.22 & 3.02 & 10.61 \\
\hline New Zealand & 0.136 & 2.91 & 0.22 & 20.66 & 0.075 & 3.58 & 4.88 & 12.31 \\
\hline Sweden & 0.053 & 1.26 & 1.32 & 4.19 & -0.059 & -1.21 & 0.63 & 8.12 \\
\hline USA & 0.047 & 0.38 & 15.16 & 1.16 & -0.090 & -0.88 & 1.52 & 7.32 \\
\hline
\end{tabular}

Notes: For each country we estimate the forecasting regressions $h_{t+1}=a_{h}+b_{h}\left(r_{t}-p_{t}\right)+$ $\varepsilon_{h, t+1}$ and $\Delta r_{t+1}=a_{r}+b_{r}\left(r_{t}-p_{t}\right)+\varepsilon_{r, t+1} . t_{N W}$ denotes the $t$-statistic based on NeweyWest standard errors. $P_{S}$ denotes the simulated p-value from the joint test and is equal to $P\left(b_{h}>\widehat{b}_{h}\right.$ and $\left.b_{r}>\widehat{b}_{r}\right)$ if the estimated predictive coefficient is positive and $P\left(b_{h}<\widehat{b}_{h}\right.$ and $\left.b_{r}<\widehat{b}_{r}\right)$ if the coefficient is negative. The p-value and $R^{2}$ are given in percent. The sample periods are the same as in Table 1. 
Table 3. Null hypotheses in the joint tests

\begin{tabular}{|c|c|c|c|c|c|c|}
\hline & \multirow[b]{2}{*}{$\rho$} & \multirow[b]{2}{*}{$\widehat{\phi}$} & \multicolumn{2}{|c|}{$H_{0}: b_{h}=0$} & \multicolumn{2}{|c|}{$H_{0}: b_{r}=0$} \\
\hline & & & $b_{h}$ & $b_{r}$ & $b_{h}$ & $b_{r}$ \\
\hline Australia & 0.924 & 0.998 & 0.000 & -0.078 & 0.078 & 0.000 \\
\hline Belgium & 0.936 & 1.034 & 0.000 & -0.033 & 0.033 & 0.000 \\
\hline Canada & 0.921 & 0.968 & 0.000 & -0.109 & 0.109 & 0.000 \\
\hline Switzerland & 0.968 & 0.921 & 0.000 & -0.109 & 0.109 & 0.000 \\
\hline Germany & 0.979 & 0.997 & 0.000 & -0.024 & 0.024 & 0.000 \\
\hline Denmark & 0.940 & 0.920 & 0.000 & -0.136 & 0.136 & 0.000 \\
\hline Spain & 0.897 & 0.937 & 0.000 & -0.160 & 0.160 & 0.000 \\
\hline Finland & 0.932 & 0.946 & 0.000 & -0.118 & 0.118 & 0.000 \\
\hline France & 0.934 & 0.995 & 0.000 & -0.071 & 0.071 & 0.000 \\
\hline UK & 0.929 & 0.914 & 0.000 & -0.151 & 0.151 & 0.000 \\
\hline Ireland & 0.877 & 0.935 & 0.000 & -0.180 & 0.180 & 0.000 \\
\hline Italy & 0.938 & 0.794 & 0.000 & -0.256 & 0.256 & 0.000 \\
\hline Japan & 0.979 & 1.020 & 0.000 & -0.001 & 0.001 & 0.000 \\
\hline Holland & 0.932 & 0.968 & 0.000 & -0.099 & 0.099 & 0.000 \\
\hline Norway & 0.922 & 0.997 & 0.000 & -0.081 & 0.081 & 0.000 \\
\hline New Zealand & 0.916 & 0.992 & 0.000 & -0.091 & 0.091 & 0.000 \\
\hline Sweden & 0.956 & 0.931 & 0.000 & -0.110 & 0.110 & 0.000 \\
\hline USA & 0.953 & 0.904 & 0.000 & -0.139 & 0.139 & 0.000 \\
\hline
\end{tabular}

Notes: In both null hypotheses, $\phi$ is set equal to the estimated value $\widehat{\phi}$, and $b_{h}$ and $b_{r}$ are calculated using the relation $b_{h}=1-\rho \phi+b_{r}$ assuming the other one is equal to zero. $\rho$ is calculated as $e^{E(\Delta r-h)}$. 
Table 4. Return and rent growth predictability using real data

\begin{tabular}{|c|c|c|c|c|c|c|c|c|}
\hline & \multicolumn{4}{|c|}{ Returns } & \multicolumn{4}{|c|}{ Rent growth } \\
\hline & $\widehat{b}_{h}$ & $t_{N W}$ & $P_{S}$ & $R^{2}$ & $\widehat{b}_{r}$ & $t_{N W}$ & $P_{S}$ & $R^{2}$ \\
\hline Australia & 0.034 & 1.16 & 1.01 & 2.48 & -0.020 & -1.49 & 0.26 & 7.78 \\
\hline Belgium & 0.038 & 1.05 & 0.10 & 3.91 & 0.021 & 3.14 & 3.91 & 14.78 \\
\hline Canada & 0.061 & 1.62 & 0.00 & 5.39 & -0.021 & -2.00 & 0.17 & 9.55 \\
\hline Switzerland & 0.085 & 1.30 & 0.00 & 5.98 & -0.024 & -1.48 & 1.06 & 4.08 \\
\hline Germany & 0.022 & 0.73 & 9.83 & 2.71 & -0.012 & -0.66 & 9.09 & 1.28 \\
\hline Denmark & 0.139 & 2.09 & 0.01 & 11.64 & 0.013 & 1.42 & 32.24 & 1.85 \\
\hline Spain & 0.090 & 2.67 & 0.00 & 18.89 & -0.042 & -4.30 & 0.00 & 42.20 \\
\hline Finland & 0.052 & 1.08 & 1.48 & 1.98 & -0.051 & -2.19 & 0.22 & 12.75 \\
\hline France & 0.048 & 1.07 & 0.08 & 3.72 & -0.004 & -0.39 & 1.18 & 0.25 \\
\hline UK & 0.165 & 3.07 & 0.00 & 17.01 & 0.032 & 3.30 & 7.15 & 6.16 \\
\hline Ireland & 0.088 & 2.79 & 0.01 & 26.66 & -0.063 & -2.39 & 0.27 & 10.80 \\
\hline Italy & 0.165 & 2.61 & 0.00 & 18.40 & -0.083 & -2.71 & 0.00 & 22.20 \\
\hline Japan & 0.020 & 0.42 & 25.56 & 0.48 & 0.009 & 0.58 & 25.44 & 1.02 \\
\hline Holland & 0.100 & 3.43 & 0.00 & 13.44 & 0.014 & 1.85 & 11.16 & 8.53 \\
\hline Norway & 0.040 & 1.05 & 0.05 & 2.35 & -0.012 & -1.36 & 0.22 & 4.00 \\
\hline New Zealand & 0.073 & 1.47 & 2.56 & 6.08 & 0.012 & 0.91 & 44.19 & 0.71 \\
\hline Sweden & 0.094 & 1.79 & 0.01 & 9.66 & -0.017 & -0.89 & 2.41 & 1.89 \\
\hline USA & 0.134 & 1.69 & 0.02 & 11.68 & -0.002 & -0.07 & 11.26 & 0.02 \\
\hline
\end{tabular}

Notes: For each country we estimate the forecasting regressions $h_{t+1}=a_{h}+b_{h}\left(r_{t}-p_{t}\right)+$ $\varepsilon_{h, t+1}$ and $\Delta r_{t+1}=a_{r}+b_{r}\left(r_{t}-p_{t}\right)+\varepsilon_{r, t+1} . t_{N W}$ denotes the $t$-statistic based on NeweyWest standard errors. $P_{S}$ denotes the simulated p-value from the joint test and is equal to $P\left(b_{h}>\widehat{b}_{h}\right.$ and $\left.b_{r}>\widehat{b}_{r}\right)$ if the estimated predictive coefficient is positive and $P\left(b_{h}<\widehat{b}_{h}\right.$ and $\left.b_{r}<\widehat{b}_{r}\right)$ if the coefficient is negative. The p-value and $R^{2}$ are given in percent. The sample periods are the same as in Table 1. 
Table 5. Inflation predictability

\begin{tabular}{lrrr}
\hline \hline & $\widehat{b}_{\pi}$ & $t_{N W}$ & \multicolumn{1}{c}{$R^{2}$} \\
\hline & & & \\
Australia & 0.074 & 3.75 & 29.86 \\
Belgium & 0.011 & 0.94 & 2.09 \\
Canada & 0.070 & 4.23 & 34.41 \\
Switzerland & -0.095 & -3.54 & 38.58 \\
Germany & -0.069 & -3.96 & 40.16 \\
Denmark & 0.017 & 0.49 & 1.02 \\
Spain & 0.091 & 5.13 & 57.91 \\
Finland & 0.101 & 3.59 & 29.65 \\
France & 0.022 & 0.52 & 1.16 \\
UK & 0.009 & 0.26 & 0.20 \\
Ireland & 0.058 & 3.73 & 28.68 \\
Italy & 0.030 & 0.54 & 1.74 \\
Japan & -0.074 & -1.83 & 11.55 \\
Holland & 0.005 & 0.25 & 0.30 \\
Norway & 0.041 & 1.60 & 16.03 \\
New Zealand & 0.063 & 2.61 & 10.77 \\
Sweden & -0.041 & -1.24 & 9.60 \\
USA & -0.087 & -1.14 & 11.78 \\
& & & \\
\hline \hline
\end{tabular}

Notes: For each country we estimate the forecasting regression $\pi_{t+1}=a_{\pi}+b_{\pi}\left(r_{t}-p_{t}\right)+$ $\varepsilon_{\pi, t+1} \cdot t_{N W}$ denotes the $t$-statistic based on Newey-West standard errors. The $R^{2}$ is given in percent. The sample periods are the same as in Table 1. 
Table 6. Return and rent growth predictability using quarterly nominal data

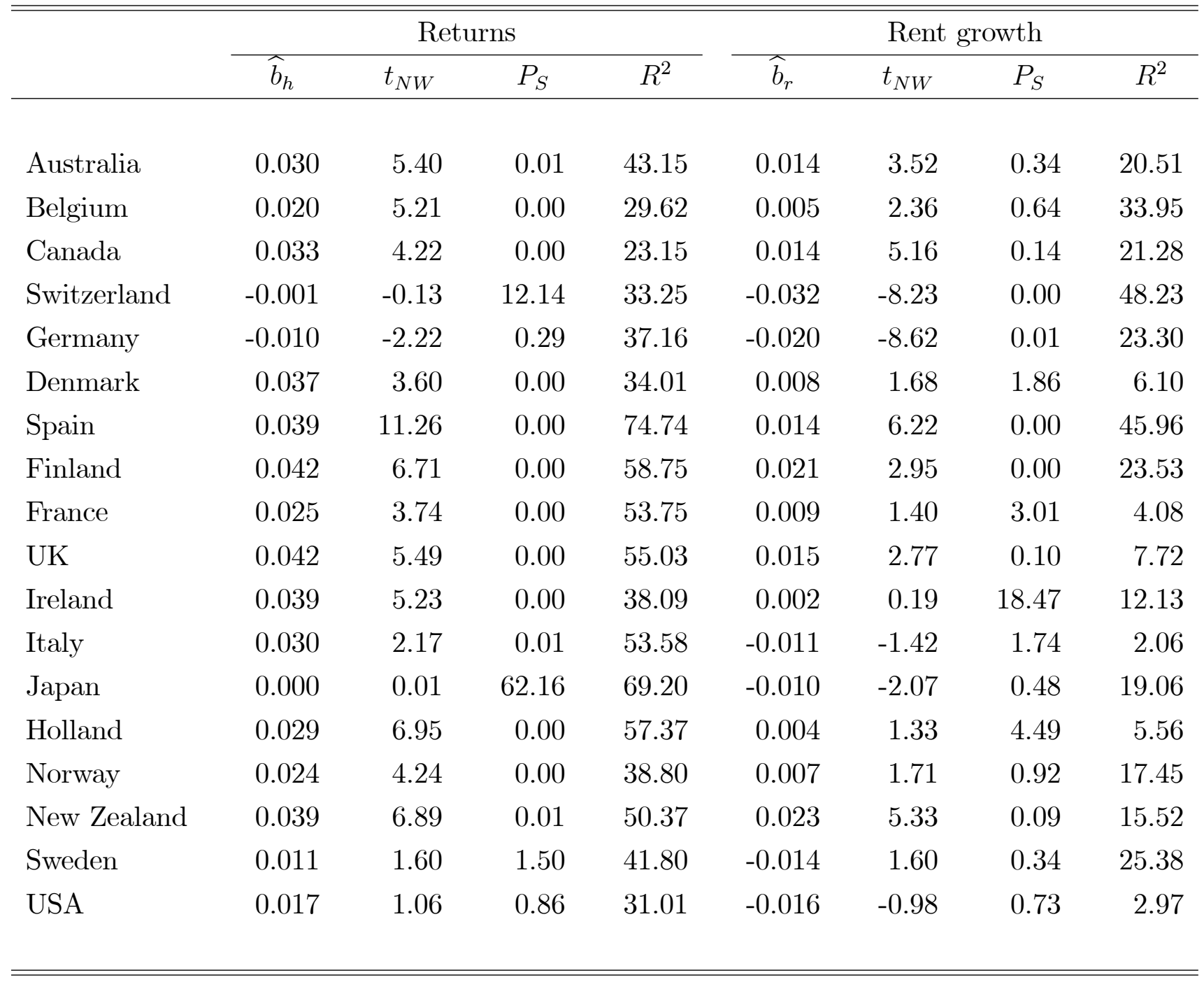

Notes: For each country we estimate the forecasting regressions $h_{t+1}=a_{h}+\sum_{i=1}^{4} b_{h, i}\left(r_{t+1-i}-p_{t+1-i}\right)+$ $\varepsilon_{h, t+1}$ and $\Delta r_{t+1}=a_{r}+\sum_{i=1}^{4} b_{r, i}\left(r_{t+1-i}-p_{t+1-i}\right)+\varepsilon_{r, t+1} . \widehat{b}_{h}$ denotes the sum of $\widehat{b}_{h, i}$ for $i=1, \ldots, 4$. Likewise for $\widehat{b}_{r}$. $t_{N W}$ denotes the $t$-statistics for $\widehat{b}_{h}$ and $\widehat{b}_{r}$ based on NeweyWest standard errors calculated using the delta method. $P_{S}$ denotes the simulated p-value from the joint test and is equal to $P\left(b_{h}>\widehat{b}_{h}\right.$ and $\left.b_{r}>\widehat{b}_{r}\right)$ if the sum of the estimated predictive coefficients is positive and $P\left(b_{h}<\widehat{b}_{h}\right.$ and $\left.b_{r}<\widehat{b}_{r}\right)$ if the sum is negative. The p-value and $R^{2}$ are given in percent. The sample periods are the same as in Table 1. 
Table 7. Return and rent growth predictability using quarterly real data

\begin{tabular}{|c|c|c|c|c|c|c|c|c|}
\hline & \multicolumn{4}{|c|}{ Returns } & \multicolumn{4}{|c|}{ Rent growth } \\
\hline & $\widehat{b}_{h}$ & $t_{N W}$ & $P_{S}$ & $R^{2}$ & $\widehat{b}_{r}$ & $t_{N W}$ & $P_{S}$ & $R^{2}$ \\
\hline Australia & 0.010 & 2.05 & 0.05 & 37.03 & -0.006 & -2.54 & 0.02 & 12.01 \\
\hline Belgium & 0.020 & 4.14 & 0.00 & 35.19 & 0.004 & 1.66 & 2.91 & 7.75 \\
\hline Canada & 0.015 & 1.95 & 0.00 & 15.28 & -0.005 & -2.01 & 0.01 & 5.95 \\
\hline Switzerland & 0.023 & 2.23 & 0.00 & 30.28 & -0.008 & -2.27 & 0.04 & 24.83 \\
\hline Germany & 0.007 & 1.59 & 4.55 & 17.15 & -0.004 & -1.33 & 10.08 & 7.18 \\
\hline Denmark & 0.031 & 3.56 & 0.00 & 34.01 & 0.002 & 0.93 & 27.06 & 0.90 \\
\hline Spain & 0.018 & 4.75 & 0.00 & 57.91 & -0.009 & -4.50 & 0.00 & 26.56 \\
\hline Finland & 0.016 & 2.61 & 0.02 & 49.75 & -0.006 & -1.32 & 0.38 & 21.39 \\
\hline France & 0.016 & 2.94 & 0.00 & 60.70 & -0.000 & -0.16 & 0.83 & 5.78 \\
\hline UK & 0.036 & 5.20 & 0.00 & 56.54 & 0.009 & 3.31 & 1.38 & 4.06 \\
\hline Ireland & 0.025 & 4.30 & 0.00 & 25.64 & -0.013 & -1.80 & 0.01 & 17.59 \\
\hline Italy & 0.023 & 2.42 & 0.02 & 53.89 & -0.018 & -2.68 & 0.03 & 11.51 \\
\hline Japan & 0.011 & 3.16 & 1.76 & 63.21 & 0.000 & 0.17 & 49.45 & 7.28 \\
\hline Holland & 0.028 & 7.21 & 0.00 & 55.89 & 0.003 & 1.31 & 10.42 & 2.88 \\
\hline Norway & 0.014 & 2.39 & 0.00 & 33.02 & -0.004 & -2.15 & 0.08 & 6.20 \\
\hline New Zealand & 0.022 & 4.12 & 0.02 & 51.38 & 0.006 & 1.72 & 8.73 & 11.29 \\
\hline Sweden & 0.019 & 3.69 & 0.04 & 57.68 & -0.006 & -1.70 & 2.59 & 9.33 \\
\hline USA & 0.032 & 3.85 & 0.00 & 39.33 & -0.001 & -0.09 & 17.48 & 0.40 \\
\hline
\end{tabular}

Notes: For each country we estimate the forecasting regressions $h_{t+1}=a_{h}+\sum_{i=1}^{4} b_{h, i}\left(r_{t+1-i}-p_{t+1-i}\right)+$ $\varepsilon_{h, t+1}$ and $\Delta r_{t+1}=a_{r}+\sum_{i=1}^{4} b_{r, i}\left(r_{t+1-i}-p_{t+1-i}\right)+\varepsilon_{r, t+1} . \widehat{b}_{h}$ denotes the sum of $\widehat{b}_{h, i}$ for $i=1, \ldots, 4$. Likewise for $\widehat{b}_{r}$. $t_{N W}$ denotes the $t$-statistics for $\widehat{b}_{h}$ and $\widehat{b}_{r}$ based on NeweyWest standard errors calculated using the delta method. $P_{S}$ denotes the simulated p-value from the joint test and is equal to $P\left(b_{h}>\widehat{b}_{h}\right.$ and $\left.b_{r}>\widehat{b}_{r}\right)$ if the sum of the estimated predictive coefficients is positive and $P\left(b_{h}<\widehat{b}_{h}\right.$ and $\left.b_{r}<\widehat{b}_{r}\right)$ if the sum is negative. The p-value and $R^{2}$ are given in percent. The sample periods are the same as in Table 1. 
Table 8. Nominal return and rent growth predictability before and after 1995

\begin{tabular}{|c|c|c|c|c|c|c|c|c|}
\hline & \multicolumn{4}{|c|}{$H_{0}: b_{h}=0$} & \multicolumn{4}{|c|}{$H_{0}: b_{r}=0$} \\
\hline & \multicolumn{2}{|c|}{$\widehat{b}_{h}$} & \multicolumn{2}{|c|}{$P_{S}$} & \multicolumn{2}{|c|}{$\widehat{b}_{r}$} & \multicolumn{2}{|c|}{$P_{S}$} \\
\hline & -1994 & 1995- & -1994 & 1995- & -1994 & 1995- & -1994 & $1995-$ \\
\hline Australia & 0.151 & 0.012 & 0.00 & 0.00 & 0.081 & -0.008 & 0.00 & 0.04 \\
\hline Belgium & 0.024 & 0.014 & 0.00 & 0.33 & -0.017 & 0.001 & 0.00 & 40.70 \\
\hline Canada & 0.059 & 0.002 & 0.00 & 2.54 & 0.009 & -0.006 & 7.11 & 0.32 \\
\hline Switzerland & 0.028 & 0.028 & 0.00 & 0.58 & -0.035 & -0.003 & 0.00 & 7.32 \\
\hline Germany & 0.018 & 0.022 & 0.87 & 0.15 & -0.002 & -0.007 & 24.71 & 0.44 \\
\hline Denmark & 0.028 & 0.025 & 0.22 & 0.00 & -0.022 & -0.001 & 0.01 & 2.54 \\
\hline Spain & 0.038 & 0.031 & 0.00 & 0.00 & 0.007 & 0.006 & 2.70 & 3.95 \\
\hline Finland & 0.051 & 0.026 & 0.00 & 0.14 & 0.015 & -0.010 & 2.73 & 1.46 \\
\hline France & 0.012 & 0.016 & 13.97 & 0.12 & -0.028 & -0.004 & 0.64 & 0.76 \\
\hline UK & 0.052 & 0.029 & 0.01 & 0.00 & -0.033 & 0.003 & 0.19 & 14.92 \\
\hline Ireland & 0.063 & 0.027 & 0.00 & 0.34 & -0.008 & -0.020 & 14.19 & 1.67 \\
\hline Italy & 0.021 & 0.032 & 0.72 & 0.00 & -0.023 & 0.010 & 0.23 & 0.19 \\
\hline Japan & 0.055 & 0.004 & 0.00 & 17.72 & 0.032 & -0.005 & 0.01 & 3.89 \\
\hline Holland & 0.025 & 0.031 & 0.06 & 0.00 & -0.017 & 0.007 & 0.09 & 1.15 \\
\hline Norway & 0.048 & 0.024 & 0.02 & 0.00 & -0.011 & 0.000 & 1.27 & 32.04 \\
\hline New Zealand & 0.038 & 0.012 & 4.10 & 0.84 & -0.045 & -0.008 & 1.16 & 0.73 \\
\hline Sweden & -0.008 & 0.020 & 8.55 & 0.05 & -0.051 & -0.001 & 0.04 & 5.95 \\
\hline USA & -0.078 & 0.030 & 0.00 & 0.00 & -0.124 & 0.003 & 0.00 & 13.61 \\
\hline
\end{tabular}

Notes: For each country we estimate the forecasting regressions $h_{t+1}=a_{h}+\sum_{i=1}^{4} b_{h, i}\left(r_{t+1-i}-p_{t+1-i}\right)+$ $\varepsilon_{h, t+1}$ and $\Delta r_{t+1}=a_{r}+\sum_{i=1}^{4} b_{r, i}\left(r_{t+1-i}-p_{t+1-i}\right)+\varepsilon_{r, t+1} . \widehat{b}_{h}$ denotes the sum of $\widehat{b}_{h, i}$ for $i=1, \ldots, 4$. Likewise for $\widehat{b}_{r}$. $P_{S}$ denotes the simulated p-value in percent from the joint test and is equal to $P\left(b_{h}>\widehat{b}_{h}\right.$ and $\left.b_{r}>\widehat{b}_{r}\right)$ if the sum of the estimated predictive coefficients is positive and $P\left(b_{h}<\widehat{b}_{h}\right.$ and $\left.b_{r}<\widehat{b}_{r}\right)$ if the sum is negative. The sample periods are the same as in Table 1. 
Table 9. Real return and rent growth predictability before and after 1995

\begin{tabular}{|c|c|c|c|c|c|c|c|c|}
\hline & \multicolumn{4}{|c|}{$H_{0}: b_{h}=0$} & \multicolumn{4}{|c|}{$H_{0}: b_{r}=0$} \\
\hline & \multicolumn{2}{|c|}{$\widehat{b}_{h}$} & \multicolumn{2}{|c|}{$P_{S}$} & \multicolumn{2}{|c|}{$\widehat{b}_{r}$} & \multicolumn{2}{|c|}{$P_{S}$} \\
\hline & -1994 & $1995-$ & -1994 & $1995-$ & -1994 & 1995- & -1994 & $1995-$ \\
\hline Australia & 0.074 & 0.015 & 0.01 & 0.33 & 0.002 & -0.005 & 36.94 & 0.63 \\
\hline Belgium & 0.035 & 0.018 & 0.00 & 3.68 & -0.005 & 0.004 & 1.74 & 32.57 \\
\hline Canada & 0.046 & 0.000 & 0.00 & 6.78 & -0.005 & -0.008 & 2.28 & 0.26 \\
\hline Switzerland & 0.043 & 0.034 & 0.00 & 1.16 & -0.021 & 0.004 & 0.00 & 32.80 \\
\hline Germany & 0.052 & 0.018 & 0.01 & 4.42 & 0.032 & -0.012 & 0.07 & 2.00 \\
\hline Denmark & 0.063 & 0.027 & 0.00 & 0.07 & 0.012 & 0.001 & 6.92 & 37.06 \\
\hline Spain & 0.019 & 0.031 & 0.19 & 0.00 & -0.013 & 0.006 & 0.04 & 9.69 \\
\hline Finland & 0.026 & 0.029 & 0.21 & 1.32 & -0.011 & -0.007 & 1.95 & 7.47 \\
\hline France & 0.038 & 0.018 & 0.06 & 0.26 & -0.002 & -0.001 & 15.80 & 4.61 \\
\hline UK & 0.092 & 0.034 & 0.00 & 0.06 & 0.008 & 0.008 & 13.75 & 12.81 \\
\hline Ireland & 0.053 & 0.026 & 0.00 & 0.18 & -0.020 & -0.021 & 2.25 & 0.39 \\
\hline Italy & 0.022 & 0.030 & 0.35 & 0.01 & -0.022 & 0.007 & 0.15 & 3.74 \\
\hline Japan & 0.031 & 0.011 & 0.40 & 22.58 & 0.007 & 0.001 & 18.51 & 43.14 \\
\hline Holland & 0.041 & 0.031 & 0.00 & 0.01 & -0.000 & 0.007 & 13.24 & 9.03 \\
\hline Norway & 0.054 & 0.023 & 0.01 & 2.15 & -0.005 & -0.000 & 6.27 & 6.07 \\
\hline New Zealand & 0.094 & 0.014 & 0.12 & 0.90 & 0.012 & -0.006 & 27.69 & 1.69 \\
\hline Sweden & 0.020 & 0.021 & 2.58 & 1.27 & -0.023 & -0.000 & 1.46 & 13.85 \\
\hline USA & 0.009 & 0.038 & 6.86 & 0.24 & -0.037 & 0.011 & 0.00 & 10.11 \\
\hline
\end{tabular}

Notes: For each country we estimate the forecasting regressions $h_{t+1}=a_{h}+\sum_{i=1}^{4} b_{h, i}\left(r_{t+1-i}-p_{t+1-i}\right)+$ $\varepsilon_{h, t+1}$ and $\Delta r_{t+1}=a_{r}+\sum_{i=1}^{4} b_{r, i}\left(r_{t+1-i}-p_{t+1-i}\right)+\varepsilon_{r, t+1} . \widehat{b}_{h}$ denotes the sum of $\widehat{b}_{h, i}$ for $i=1, \ldots, 4$. Likewise for $\widehat{b}_{r}$. $P_{S}$ denotes the simulated p-value in percent from the joint test and is equal to $P\left(b_{h}>\widehat{b}_{h}\right.$ and $\left.b_{r}>\widehat{b}_{r}\right)$ if the sum of the estimated predictive coefficients is positive and $P\left(b_{h}<\widehat{b}_{h}\right.$ and $\left.b_{r}<\widehat{b}_{r}\right)$ if the sum is negative. The sample periods are the same as in Table 1. 


\section{Appendix}

Figure 1A. Joint distribution of the return and rent growth coefficients under the hypotheses of no predictability using nominal data.
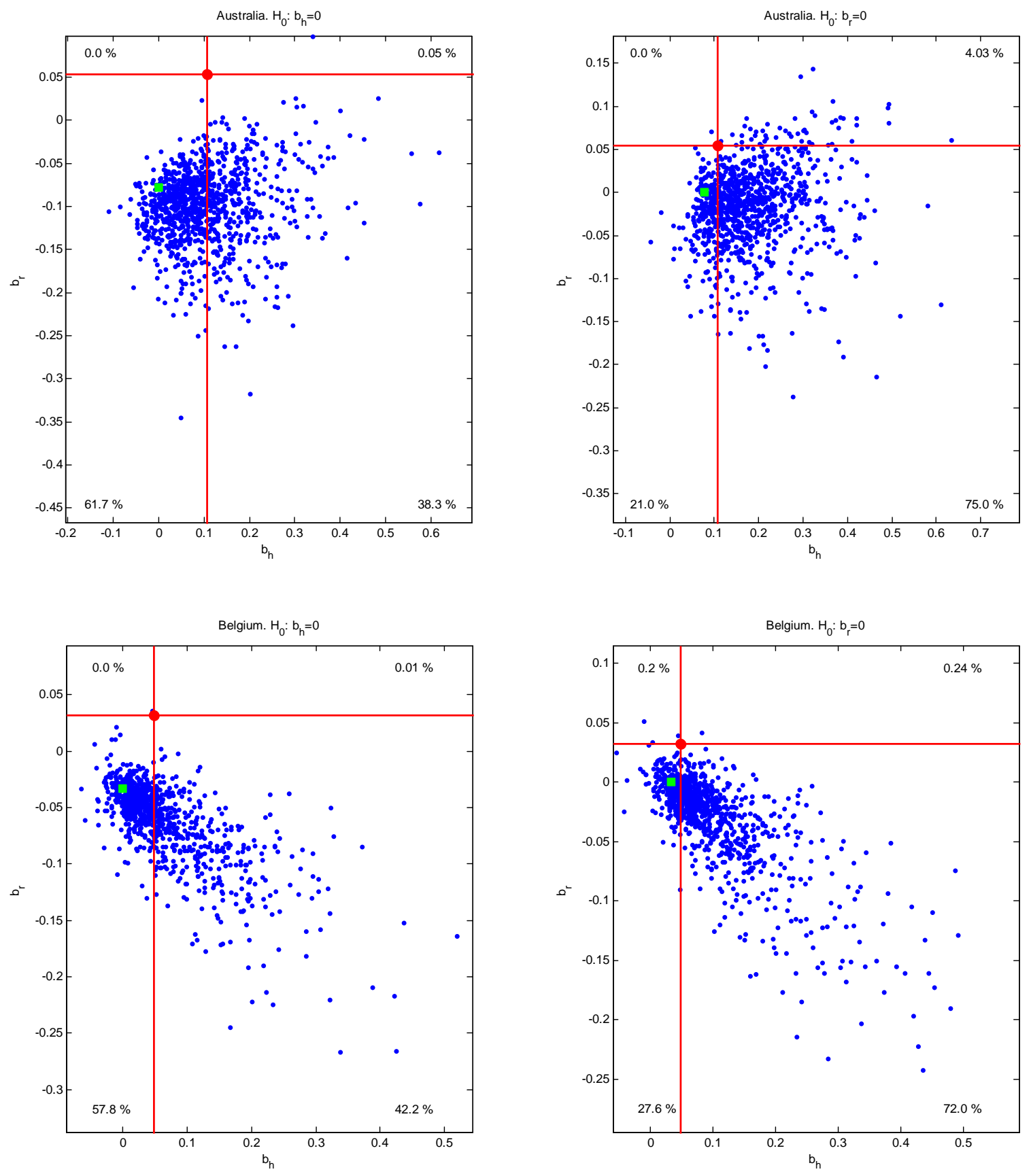

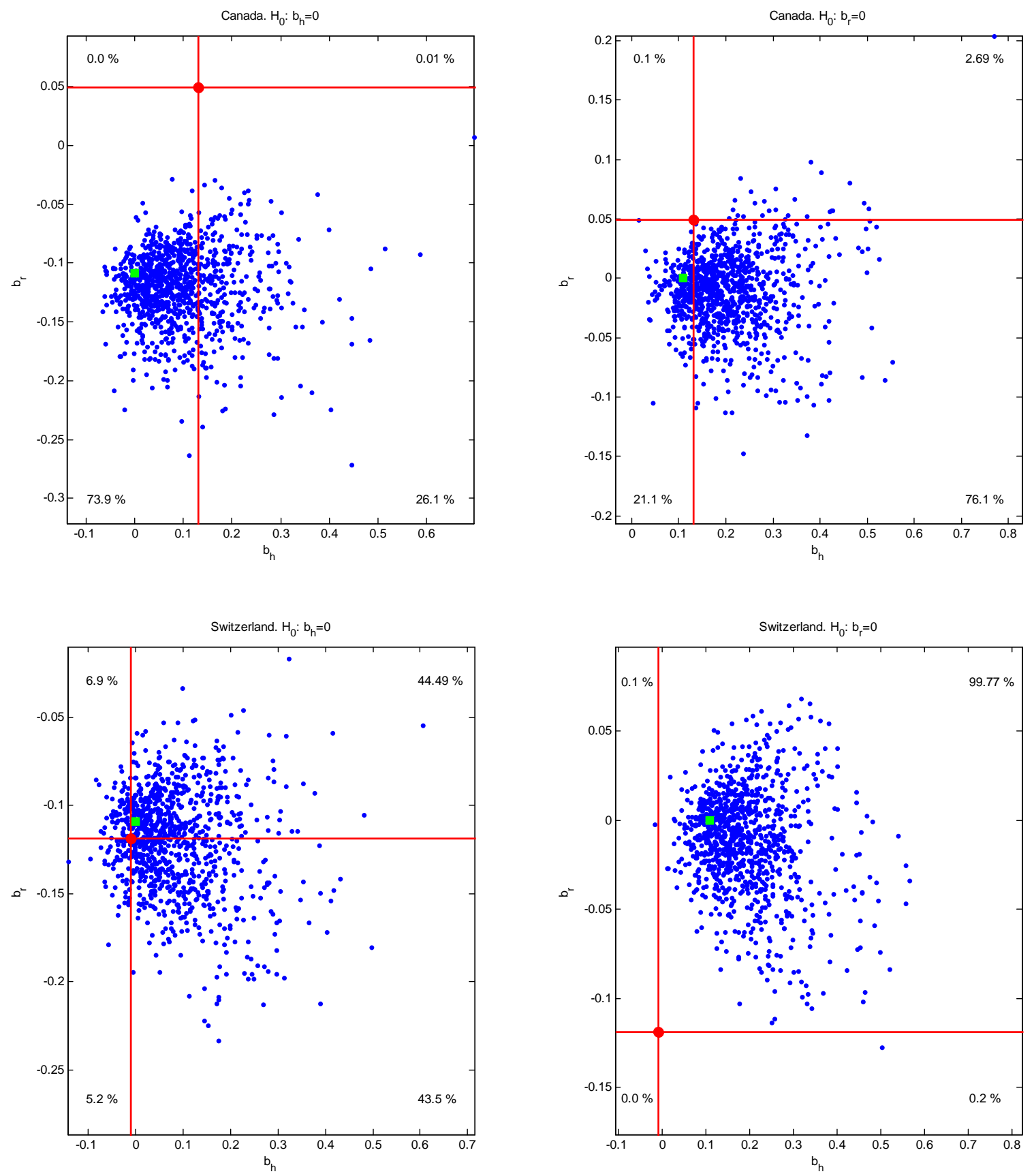

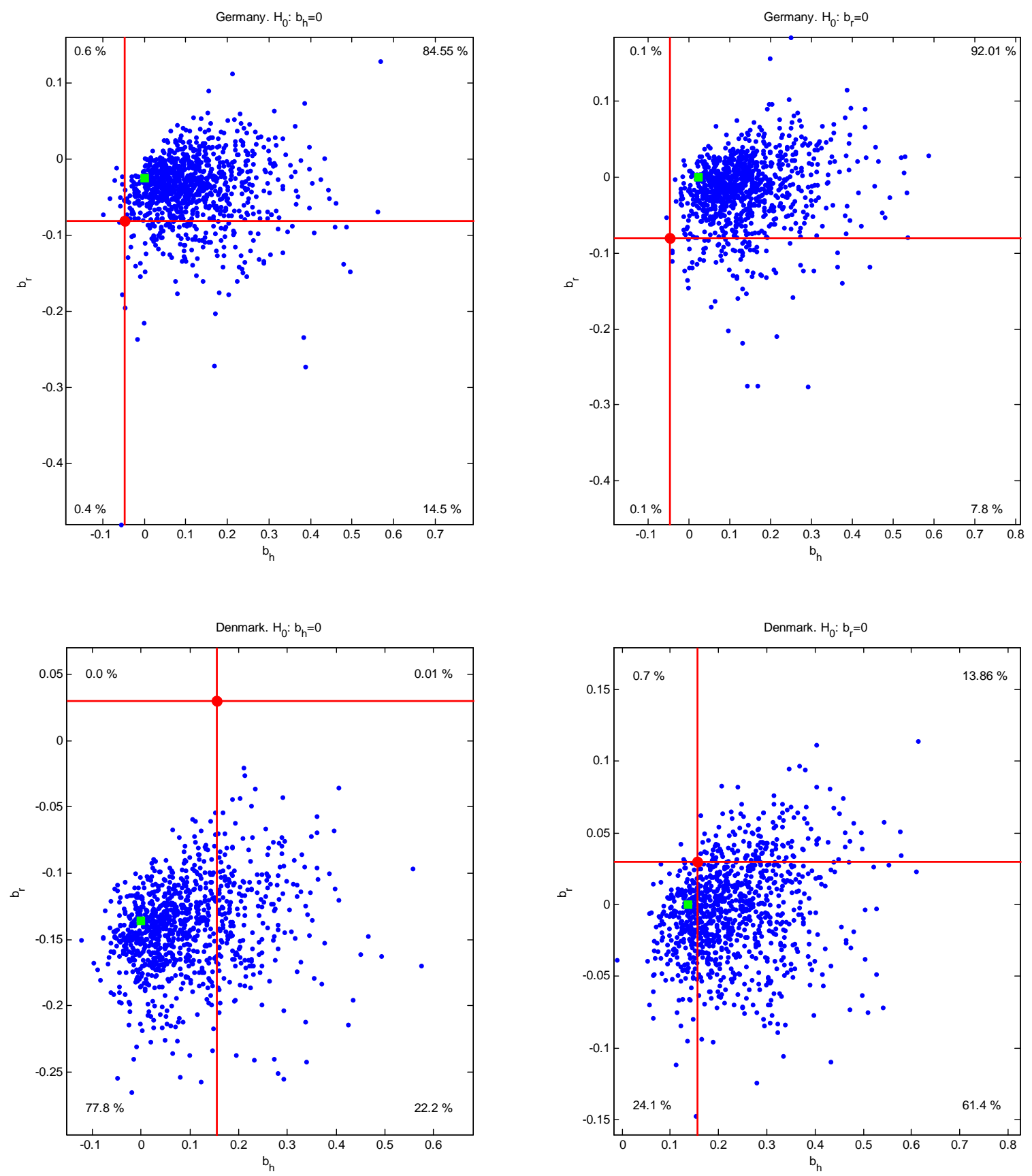

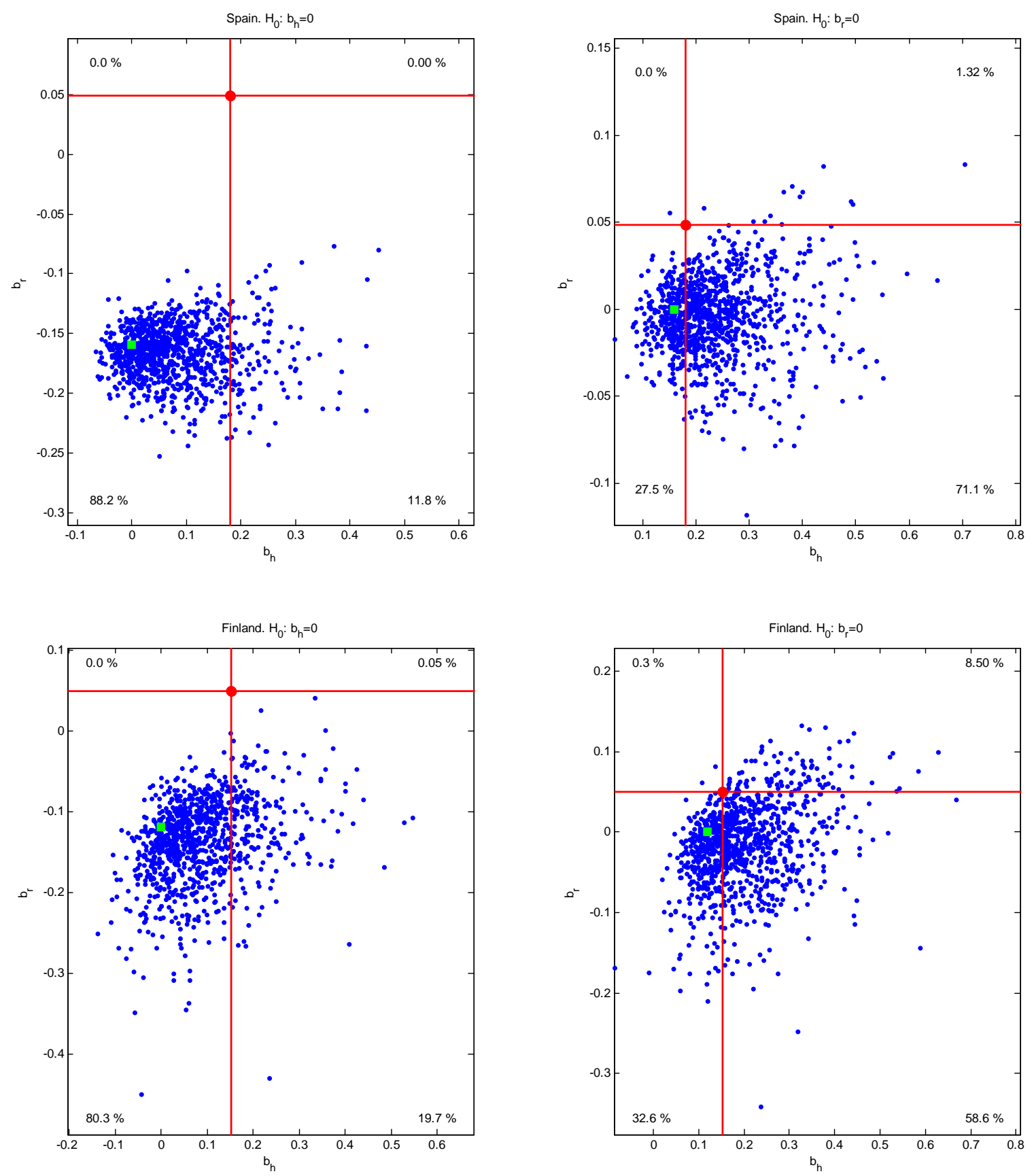

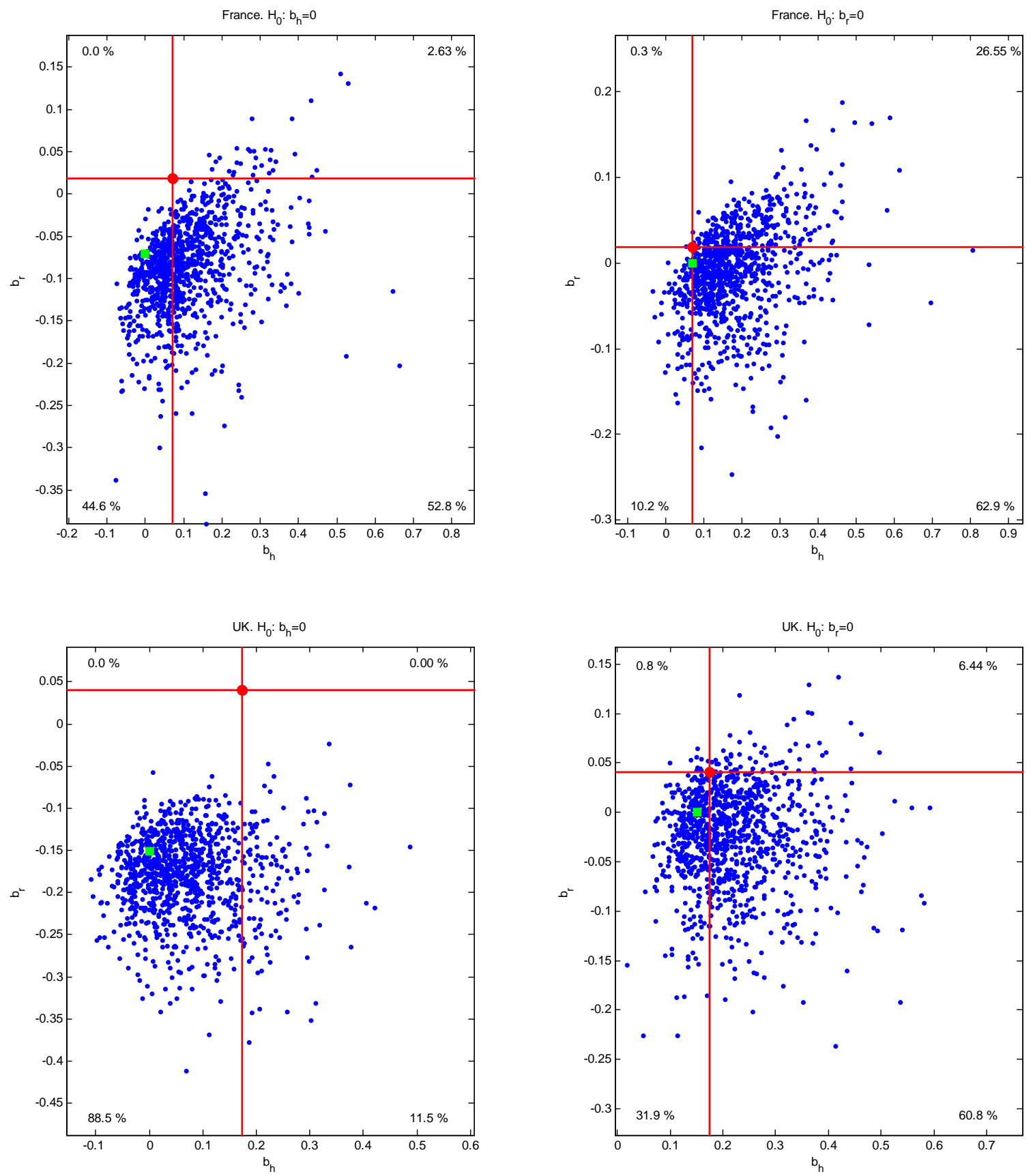

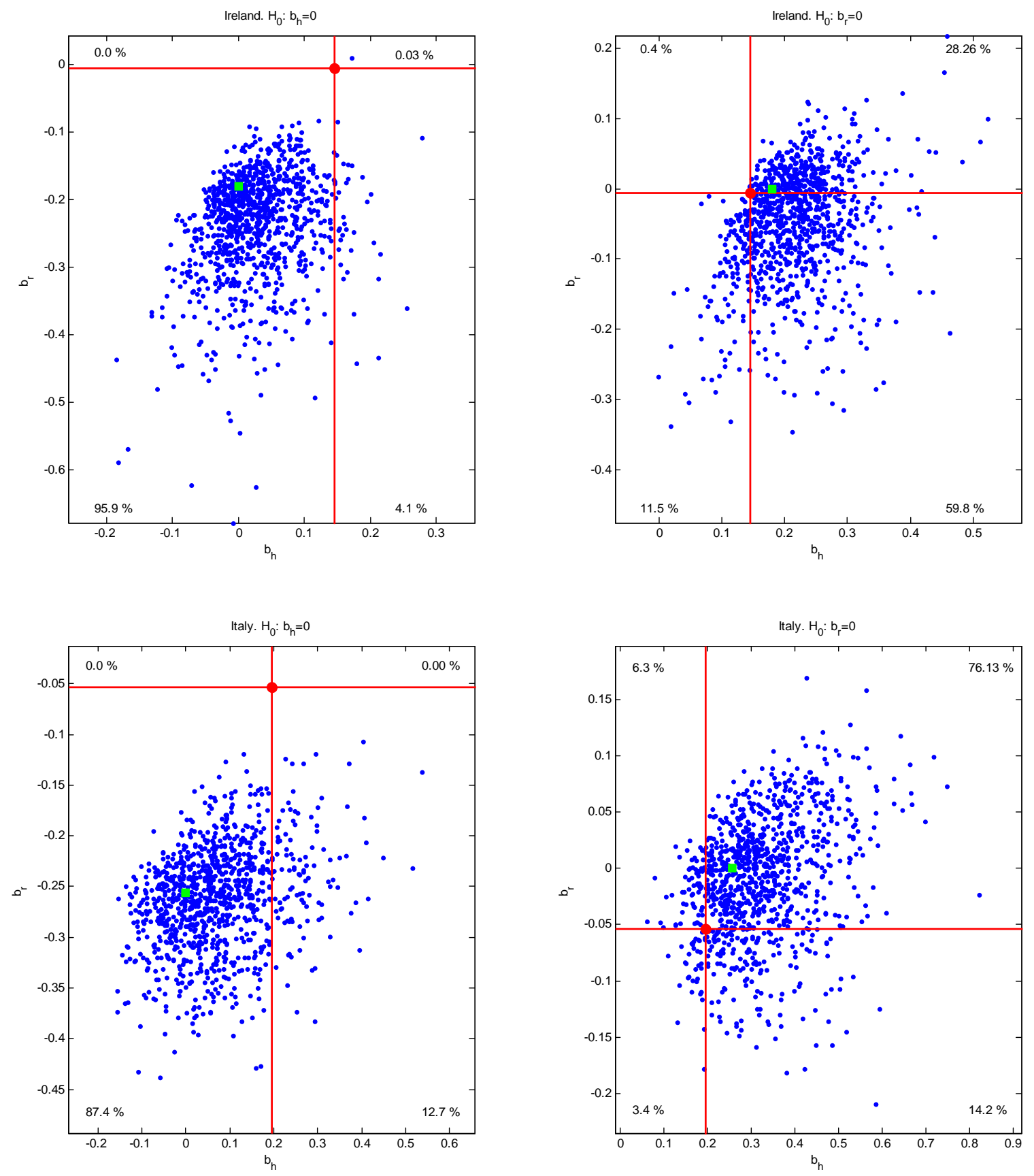

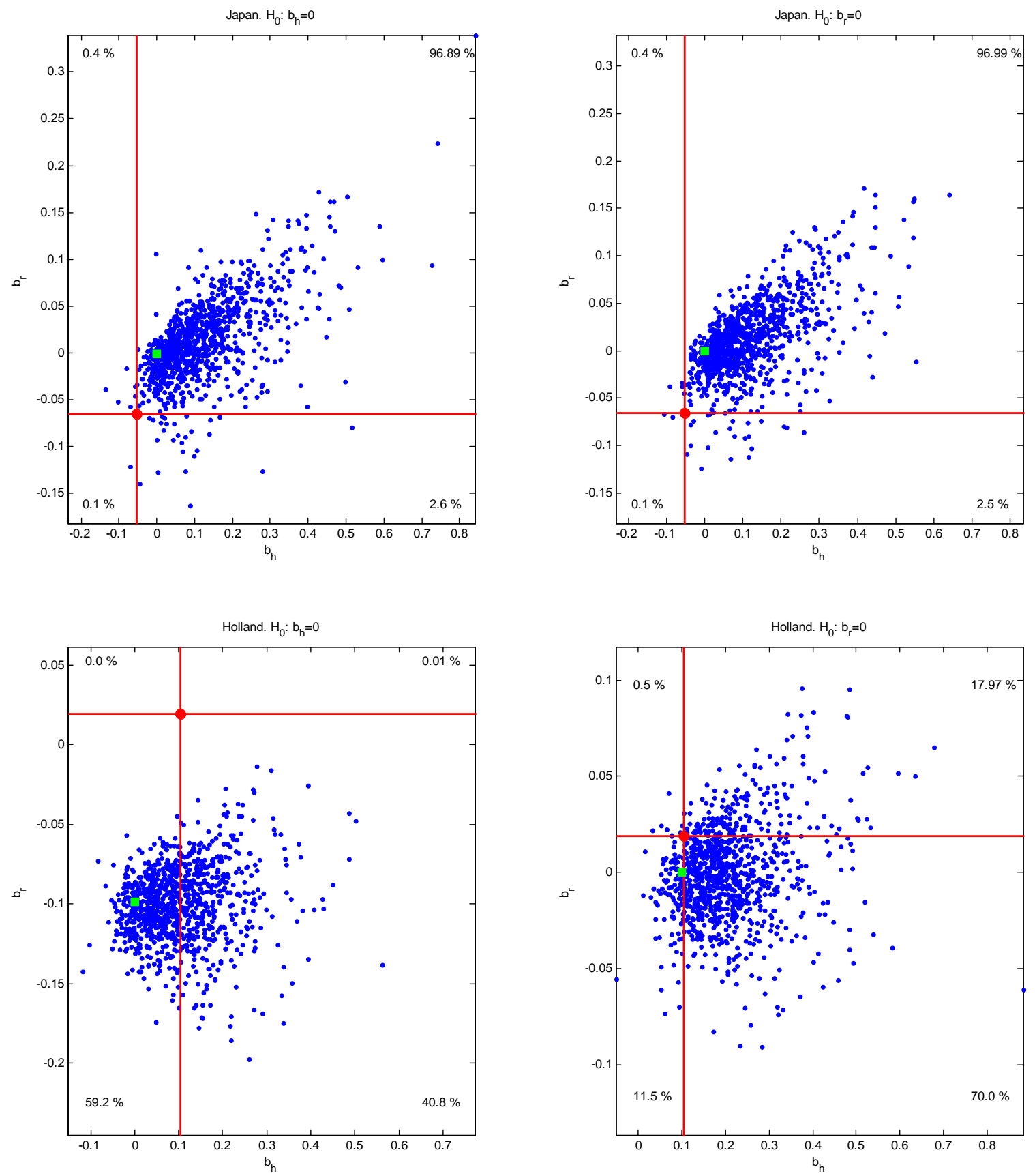

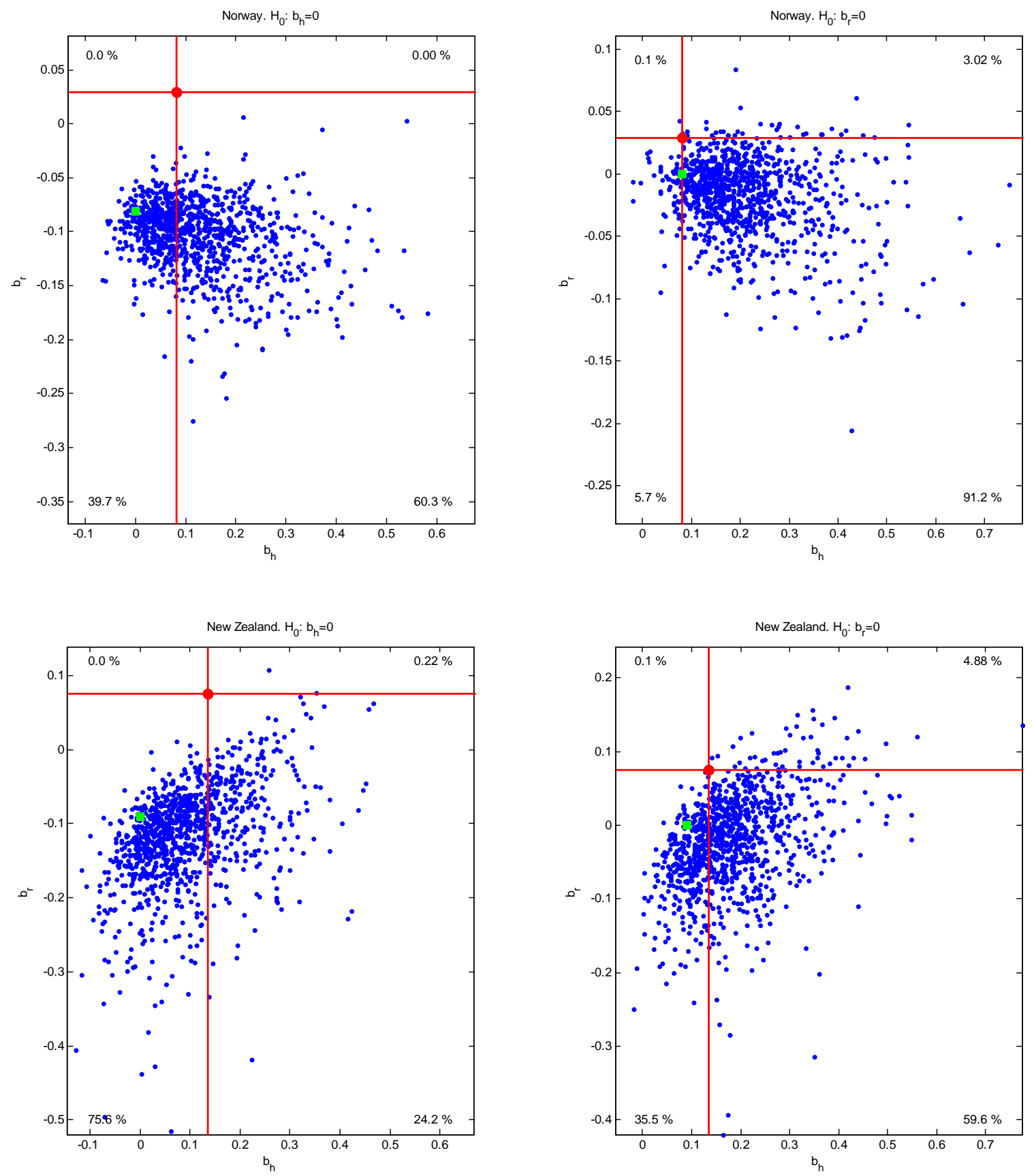

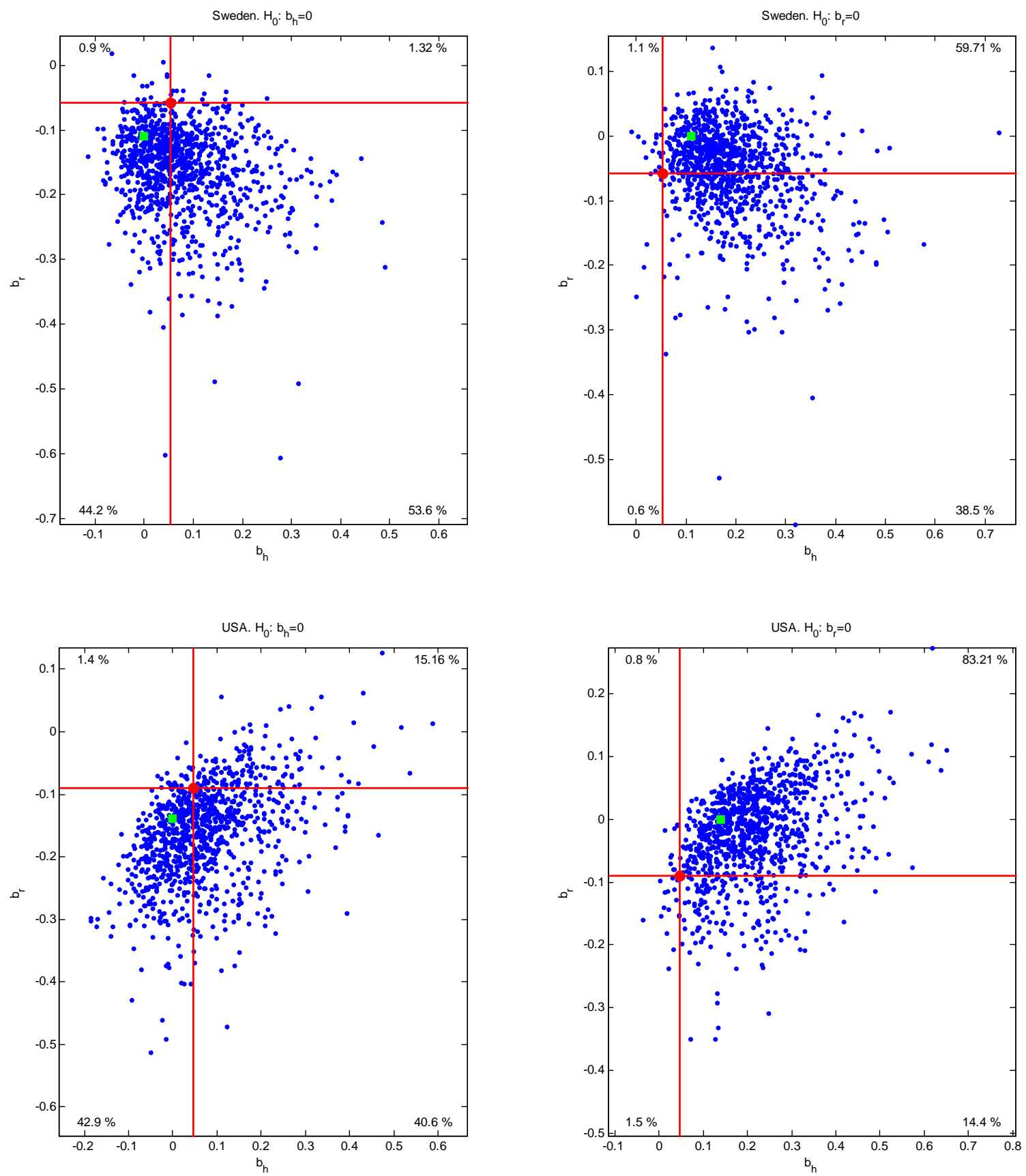

Notes: The lines and large dots give the sample estimates. The square gives the null. 1,000 simulations are plotted for clarity. The number in each quadrant is the fraction of 10,000 simulations that falls within the quadrant. 
2012-42: $\quad$ Stig V. Møller and Jesper Rangvid: End-of-the-year economic growth and time-varying expected returns

2012-43: $\quad$ Peter Reinhard Hansen and Allan Timmermann: Choice of Sample Split in Out-of-Sample Forecast Evaluation

2012-44: Peter Reinhard Hansen and Zhuo Huang: Exponential GARCH Modeling with Realized Measures of Volatility Statistics

2012-45: $\quad$ Peter Reinhard Hansen and Allan Timmermann: Equivalence Between Out-ofSample Forecast Comparisons and Wald

2012-46: $\quad$ Søren Johansen, Marco Riani and Anthony C. Atkinson: The Selection of ARIMA Models with or without Regressors

2012-47: $\quad$ Søren Johansen and Morten Ørregaard Nielsen: The role of initial values in nonstationary fractional time series models

2012-48: $\quad$ Peter Christoffersen, Vihang Errunza, Kris Jacobs and Hugues Langlois: Is the Potential for International Diversi...cation Disappearing? A Dynamic Copula Approach

2012-49: $\quad$ Peter Christoffersen, Christian Dorion, Kris Jacobs and Lotfi Karoui: Nonlinear Kalman Filtering in Affine Term Structure Models

2012-50: Peter Christoffersen, Kris Jacobs and Chayawat Ornthanalai: GARCH Option Valuation: Theory and Evidence

2012-51: Tim Bollerslev, Lai Xu and Hao Zhou: Stock Return and Cash Flow Predictability: The Role of Volatility Risk

2012-52: José Manuel Corcuera, Emil Hedevang, Mikko S. Pakkanen and Mark Podolskij: Asymptotic theory for Brownian semi-stationary processes with application to turbulence

2012-53: $\quad$ Rasmus Søndergaard Pedersen and Anders Rahbek: Multivariate Variance Targeting in the BEKK-GARCH Model

2012-54: Matthew T. Holt and Timo Teräsvirta: Global Hemispheric Temperature Trends and Co-Shifting: A Shifting Mean Vector Autoregressive Analysis

2012-55: Daniel J. Nordman, Helle Bunzel and Soumendra N. Lahiri: A Non-standard Empirical Likelihood for Time Series

2012-56: $\quad$ Robert F. Engle, Martin Klint Hansen and Asger Lunde: And Now, The Rest of the News: Volatility and Firm Specific News Arrival

2012-57: Jean Jacod and Mark Podolskij: A test for the rank of the volatility process: the random perturbation approach

2012-58: $\quad$ Tom Engsted and Thomas Q. Pedersen: Predicting returns and rent growth in the housing market using the rent-to-price ratio: Evidence from the OECD countries 